\title{
Mitochondrial ATP transporter Ant2 depletion impairs erythropoiesis and $B$ lymphopoiesis
}

\author{
J Cho ${ }^{1,6}$, J Seo ${ }^{2,6}$, CH Lim ${ }^{1}$, L Yang ${ }^{1}$, T Shiratsuchi ${ }^{3}$, M-H Lee ${ }^{4}$, RR Chowdhury ${ }^{5}$, H Kasahara ${ }^{5}$, J-S Kim ${ }^{4}$, SP Oh ${ }^{2,5}$, YJ Lee ${ }^{*, 2}$ \\ and $\mathrm{N}$ Terada ${ }^{\star, 1}$
}

\begin{abstract}
Adenine nucleotide translocases (ANTs) transport ADP and ATP through mitochondrial inner membrane, thus playing an essential role for energy metabolism of eukaryotic cells. Mice have three ANT paralogs, Ant1 (SIc25a4), Ant2 (SIc25a5) and Ant4 (SIc25a31), which are expressed in a tissue-dependent manner. While knockout mice have been characterized with Ant1 and Ant4 genes, which resulted in exercise intolerance and male infertility, respectively, the role of the ubiquitously expressed Ant2 gene in animal development has not been fully demonstrated. Here, we generated Ant2 hypomorphic mice by targeted disruption of the gene, in which Ant2 expression is largely depleted. The mice showed apparently normal embryonic development except pale phenotype along with a reduced birth rate. However, postnatal growth was severely retarded with macrocytic anemia, B lymphocytopenia, lactic acidosis and bloated stomach, and died within 4 weeks. Ant2 depletion caused anemia in a cell-autonomous manner by maturation arrest of erythroid precursors with increased reactive oxygen species and premature deaths. B-lymphocyte development was similarly affected by Ant2 depletion, and splenocytes showed a reduction in maximal respiration capacity and cellular ATP levels as well as an increase in cell death accompanying mitochondrial permeability transition pore opening. In contrast, myeloid, megakaryocyte and T-lymphocyte lineages remained apparently intact. Erythroid and B-cell development may be particularly vulnerable to Ant2 depletion-mediated mitochondrial dysfunction and oxidative stress.
\end{abstract}

Cell Death and Differentiation (2015) 22, 1437-1450; doi:10.1038/cdd.2014.230; published online 23 January 2015

Adenine nucleotide translocases (ANTs) facilitate the transport of ADP/ATP across the mitochondrial inner membrane, thus playing an essential role in the supply of mitochondrial ATP to the cytoplasm. ${ }^{1,2}$ In respiratory conditions, ATP generated through oxidative phosphorylation within mitochondria is transported out to the cytosol, while ADP in return is imported through ANTs. ${ }^{3,4}$ ANTs are nuclear-encoded proteins weighing $30-35 \mathrm{kDa}$ and are most abundant protein in the inner mitochondrial membrane. ${ }^{5}$ From yeast to mammals, all eukaryotes have multiple ANT paralogs and their redundant or differential functions remain controversial. In higher eukaryotes, ANT paralogs are often expressed in a tissuespecific manner, and considered to be adapted to particular cellular energetic demand. ${ }^{6}$ However, kinetics for their ADP/ ATP exchange activity is largely similar between paralogs, or variable depending on the studies. ${ }^{7}$ There has been no clear experimental evidence to date that differential ATP transport kinetics among the paralogs are critical for their specific roles in cells or tissues. Besides ATP transport activity, multiple studies indicate ANT paralogs may differ in their intramitochondrial sublocalization, ${ }^{8}$ uncoupling activities, ${ }^{9}$ binding partners ${ }^{10}$ and effects on mitochondrial permeability transition pore (mPTP) opening and subsequent cellular survival and death control. ${ }^{11}$ These intriguing subjects, however, have not been confirmed rigorously after the initial reports. Thus, redundant or differential functions of multiple ANT paralogs are still largely controversial to date.

Targeted gene disruption studies in model animals have provided important information as to the roles of individual ANT paralogs for different organ systems. Mice have three Ant paralogs (Ant1, Ant2 and Ant4), the transcription of which depends on tissue types and developmental stages. ${ }^{12}$ Although both Ant1 and Ant2 transcripts are detected in most organs of mice, ${ }^{13,14}$ Ant 1 is particularly highly expressed in the

\footnotetext{
${ }^{1}$ Department of Pathology, University of Florida College of Medicine, Gainesville, FL, USA; ${ }^{2}$ Lee Gil Ya Cancer and Diabetes Institute, Gachon University, Incheon, South Korea; ${ }^{3}$ Otsuka Maryland Medicinal Laboratories, Rockville, MD, USA; ${ }^{4}$ Department of Surgery, University of Florida College of Medicine, Gainesville, FL, USA and ${ }^{5}$ Department of Physiology, University of Florida College of Medicine, Gainesville, FL, USA

*Corresponding author: YJ Lee, Lee Gil Ya Cancer and Diabetes Institute, Gachon University, 7-45 Songdo-Dong, Yunsu-Gu, Incheon 406-840, Republic of Korea. Tel: +82 32899 6590; Fax: +82 32899 6039; E-mail: leeyj@gachon.ac.kr

or N Terada, Department of Pathology, University of Florida College of Medicine, Box 100275, 1600 Archer Road, Gainesville, 32610 FL, USA. Tel: +1 352392 2696; Fax: +1 352392 3053; E-mail: terada@ @athology.ufl.edu

${ }^{6}$ These authors contributed equally to this work.

Abbreviations: 7AAD, 7-aminoactinomycin D; ANT, adenine nucleotide translocase; BM, bone marrow; CFU-E, colony-forming unit-erythroid; CFU-GM, colony-forming unit-granulocyte macrophage; CsA, cyclosporin A; ECAR, extracellular acidification rate; ES cell, embryonic stem cell; FCCP, fluoro-carbonyl cyanide phenylhydrazone; FL, fetal liver; GI, gastrointestinal; HCT, hematocrit; HGB, hemoglobin; HSV-TK, herpes simplex virus thymidine kinase; IRES, internal ribosome entry site; LSK, lineagenegative Sca1 and c-Kit positive; MCV, mean corpuscular volume; MNGIE, mitochondrial neurogastrointestinal encephalopathy; mPTP, mitochondrial permeability transition pore; mtDNA, mitochondrial deoxyribonucleic acid; OCR, oxygen consumption rate; PARP, poly ADP ribose polymerase; PB, peripheral blood; $\mathrm{PI}$, propidium iodide; POLG, polymerase $\gamma$; RBC, red blood cell; RDW, red blood cell distribution width; ROS, reactive oxygen species; SIBN, splicing acceptor-IRES$\beta$-galactosidase-neomycin; SOD, superoxide dismutase; TMRM, tetramethyl rhodamine methyl ester; TP, thymidine phosphorylase; TUNEL, terminal deoxynuclotidyl transferase-mediated dUTP nick-end labeling; WT, wild type

Received 07.4.14; revised 13.11.14; accepted 05.12.14; Edited by S Fulda; published online 23.1.15
} 
skeletal muscle and heart, while Ant2 is rather ubiquitously expressed in all the somatic tissues. ${ }^{12,13}$ In contrast, Ant4 is exclusively expressed in meiotic germ cells and repressed in somatic tissues. ${ }^{15-17}$ Non-rodent mammals including humans have an additional paralog Ant3 (Slc25a6), which is as ubiquitously expressed like Ant2. In humans, ANT2 is induced by cell proliferation, while ANT3 is rather constitutively expressed. ${ }^{18}$ The roles of Ant1 and Ant4 in mice have been well characterized through gene disruption studies. Ant1 knockout mice were born apparently normal but developed severe exercise intolerance and cardiac hypertrophy in adult stages accompanied with skeletal and cardiac myopathy. ${ }^{19}$ Ant4 knockout mice were also born and grew normally without showing any abnormality except male infertility. ${ }^{16}$ Spermatogenesis was severely impaired by Ant4 gene disruption, and the mice failed to generate mature spermatozoa. ${ }^{16,20}$ These phenotypes of Ant1 and Ant4 knockout mice are consistent with their conserved gene expression profiles, confirming their indispensable roles in specific tissues.

In contrast to Ant1 and Ant4, the role of the Ant2 isoform in animal development and organ homeostasis has not been fully demonstrated in the literature. Kokoszka et al. ${ }^{21}$ generated Ant2 conditional knockout mice and used the mice to generate Ant1 and Ant2 double-knockout liver to characterize the role of ANT in the mPTP. ${ }^{21}$ However, to date, the group has not described general phenotypes of Ant2 knockout mice in the scientific literature. To that end, we decided to generate Ant2 knockout mice independently to determine its role in mouse development and organ homeostasis.

\section{Result}

Targeted disruption of Ant2 gene. We generated an Ant2 conditional knockout allele as shown in Figure 1a. The knockout construct was transfected into male murine ES cells, and correct homologous recombination was confirmed by Southern blot analysis (Supplementary Figure S1). Correct excision of the splicing acceptor-IRES- $\beta$-galactosidase-neomycin (SIBN) cassette and exons 2 and 3 by Flp- and Cre-recombinase in vitro, respectively, also was confirmed by Southern blot and PCR analysis (Figure 1b). As the Ant2 gene is located on the $\mathrm{X}$ chromosome, male cells are hemizygous for the gene. Thus, the resultant ES cell clones have one $A n t 2^{S I B N}, A n t 2^{2 f}$ and $A n t 2^{1 f}$ allele with no wild-type (WT) Ant2 allele. We confirmed that Ant2 gene expression was not detectable in $A n t 2^{1 f / Y}$ ES cells at the mRNA level, whereas $A n t 2^{2 f / Y}$ ES cells expressed normal levels of Ant2 as expected (Figure 1c). The insertion of an
SIBN cassette into an intron of certain genes often interferes with the transcription and/or splicing of endogenous gene, resulting in the reduction of gene expression. ${ }^{22}$ Ant2 mRNA expression was indeed decreased in $A n t 2^{S I B N / Y}$ ES cells over $98 \%$. These data indicate that the insertion of the SIBN cassette into intron 3 affects the expression of Ant2 and that $A n t 2^{S I B N}$ is a hypomorphic allele. It should be noted here that we were not able to detect $\beta$-gal expression in Ant2 ${ }^{S I B N / Y}$ ES cells or the resultant mice described below for unknown reasons.

Ant2 depletion causes postnatal growth retardation and premature death. Since we found the Ant2 $2^{S I B N / Y}$ allele is hypomorphic, we decided to initially characterize the phenotypes of Ant2 hypomorphic animals. Female mice heterozygous for the SIBN allele $\left(A n t 2^{S I B N /+}\right)$ were fertile and outwardly indistinguishable from WT controls at least up to 1 year. When $A n t 2^{S I B N /+}$ female mice were crossed with WT males, Ant $2^{S I B N / Y}$ male pups were born, but with a distinct pale phenotype (Figure 1d). At birth, the Ant2 ${ }^{S I B N / Y}$ mice were similar in size with littermates, and did not show apparent anomalies other than their pale appearance. Birth rates were approximately half of the expected Mendelian ratio (Table 1), indicating that the other half of $A n t 2^{S I B N / Y}$ mice died during embryogenesis. When embryos were examined by timed mating, embryonic day 16.5 (E16.5) Ant2 ${ }^{S I B N / Y}$ embryos demonstrated a pale phenotype too (Figure 1e). In contrast to their relatively mild phenotype at birth, postnatal growth of the $A n t 2^{S I B N / Y}$ mice was progressively retarded, and by the age of 3 weeks, body weight became approximately one-third of control littermates (Figures $1 \mathrm{f}$ and $\mathrm{g}$ ). In gross anatomy, $A n t 2^{S I B N / Y}$ mice showed no apparent anatomical anomalies besides their smaller sizes. Most organs including kidney, spleen, liver, heart and gastrointestinal (GI) tract were proportionally smaller in size and demonstrated a paler color when compared with those from control littermates at postnatal day 18 (P18) (Supplementary Figures S2A and F). Exceptionally, we observed an enlarged stomach, which was full of milk in the Ant2 $2^{\text {SIBN/Y }}$ neonates (Supplementary Figure S2E). The bloated stomach accompanied a thinner intima and media with epithelial atrophy without any signs of inflammation (Supplementary Figure S3A). In histological analyses, neonatal heart (P0) demonstrated some abnormalities including biventricular hypertrophy and noncompaction of the dorsal part of the muscular ventricular septum with ventricular septal defect (Supplementary Figure S3B). In contrast, kidney, spleen, liver and bone showed no overt structural differences (Supplementary Figures S3C and $\mathrm{F}$ ). The mice were generally active

Figure 1 Targeted disruption of the mouse Ant2 gene. (a) Schematic diagram of the WT Ant2 allele, the Ant2 conditional knockout (cKO) vector and the resultant Ant2 mutant alleles $\left(A n t 2^{S I B N}, A n t 2^{2 f}\right.$ and $\left.A n t 2^{1 t}\right)$. A splicing accepter-IRES- $\beta$ gal-neo (SIBN) cassette flanked by frt (half circle) and loxP (triangle) sequences was inserted into intron 3 . Another loxP sequence was inserted upstream of exon 2. EcoRV (E) and Ndel (N) restriction sites are indicated. (b) Genotyping of the targeted Ant2 alleles by PCR. The genomic DNA described above was subjected to PCR amplification. The predicted sizes for the PCR amplicons are indicated. (c) Transcriptional levels of Ant2 by quantitative reverse transcription-PCR (RT-PCR). RNA was extracted from $A n t 2^{+Y}(\mathrm{WT}), A n t 2^{S / B N / Y}$, Ant2 ${ }^{2 f Y}$ and Ant2 ${ }^{1 f \gamma}$ ES cells and subjected to real-time RT-PCR. Relative expression levels of Ant2 gene to $\beta$-actin using the comparative Ct method are shown. Error bars indicate S.D. (d, e) Phenotypes of Ant2 hypomorphic mice. Ant2 hypomorphic mice (Ant2 ${ }^{S / B N / Y}$ ) were paler than WT Ant2 ${ }^{X Y}$ siblings but did not show any apparent abnormalities or growth retardation at E16.5 and P1. Red arrow indicates Ant2 ${ }^{S / B N / Y}$ mouse. (f) Ant2 ${ }^{S / B N Y}$ mice showed severe growth retardation at P21. Millimeter rulers are shown as scale reference. (g) Postnatal growth curve of WT and Ant2 ${ }^{S / B N / Y}$ mice is shown by body weight (g). $N>10$ for each time point except P27 of $A n t 2^{2 S B N / Y}(n=3)$. (h) Survival curve of WT and Ant2 ${ }^{S B N / Y}$ mice $(n=41$ for each group) 
a

Ant2 allele

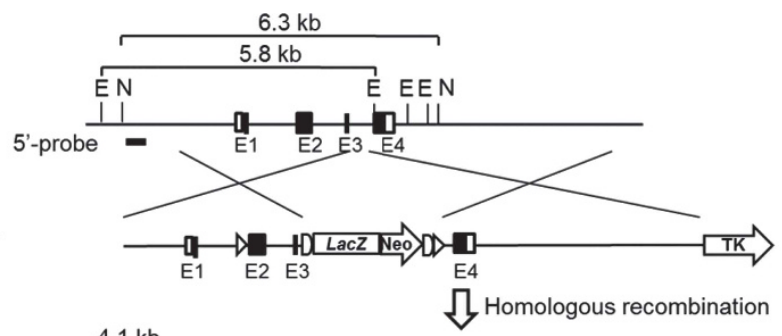

Ant2 cKO vector

Homologous recombination

Ant2 ${ }^{S I B N}$ allele

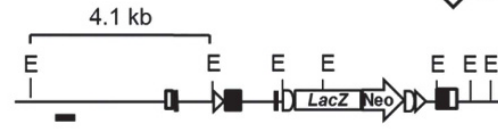

E:EcoRV

ЉIp-fit recombination

$\mathrm{N}: \mathrm{Ndel}$

Ant2 ${ }^{2 f}$ allele

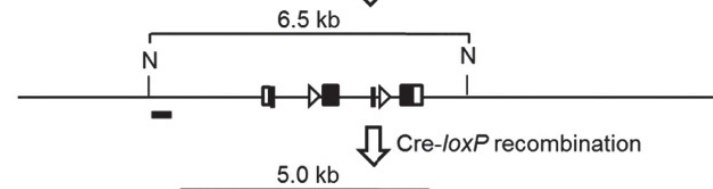

Ant2 ${ }^{1 f}$ allele

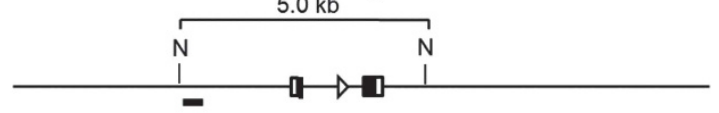

b

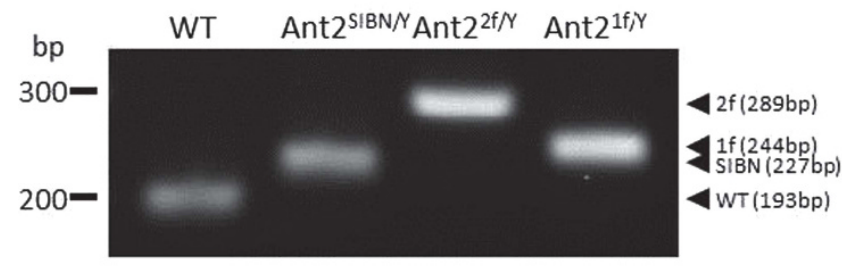

d

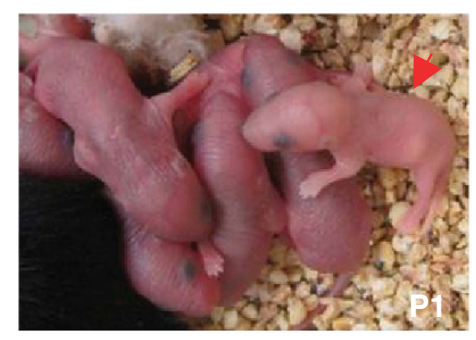

g

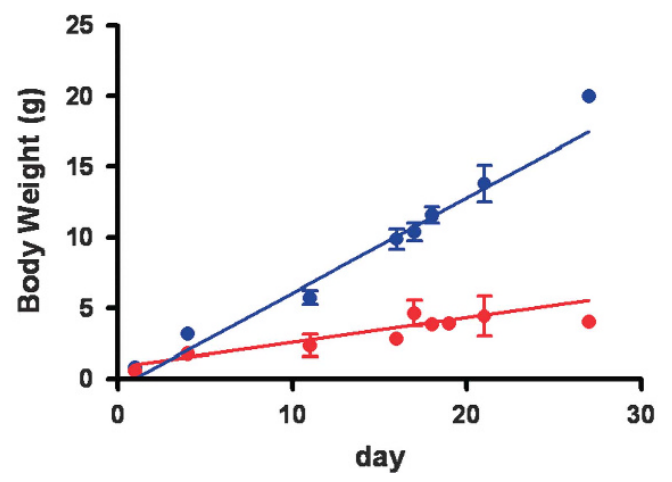

e

h
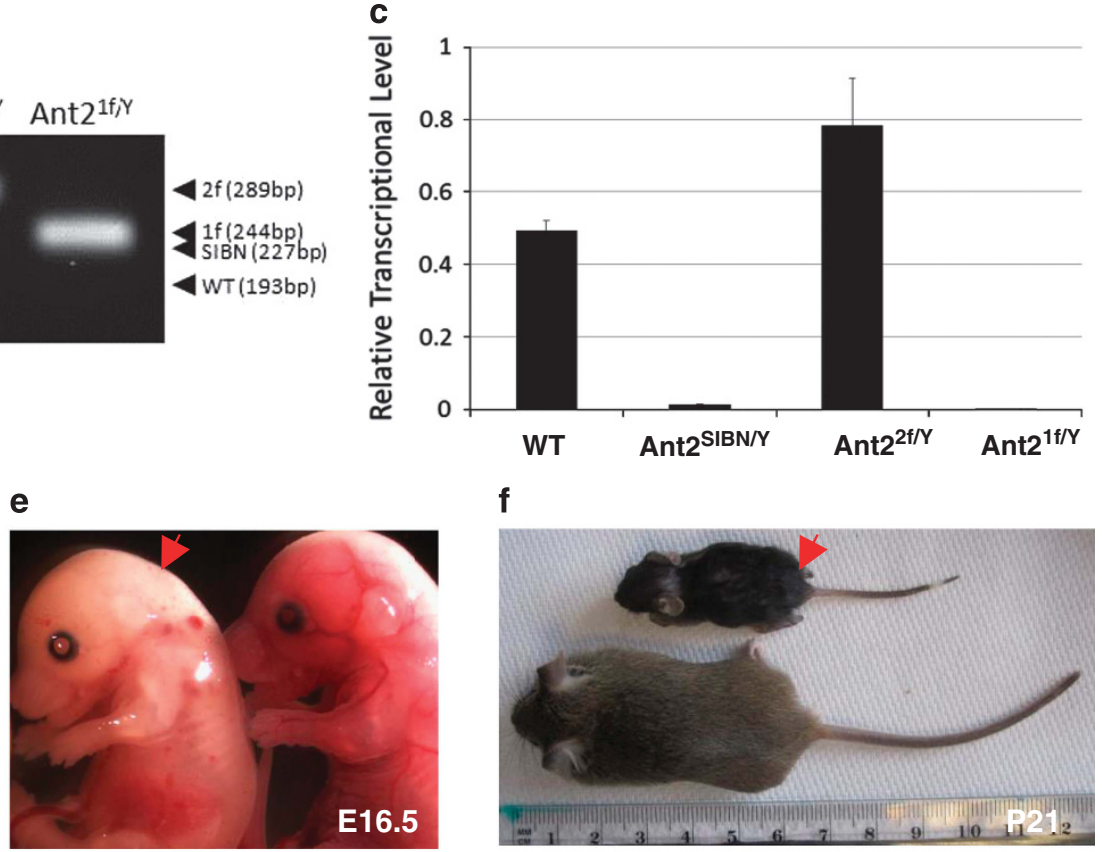

f
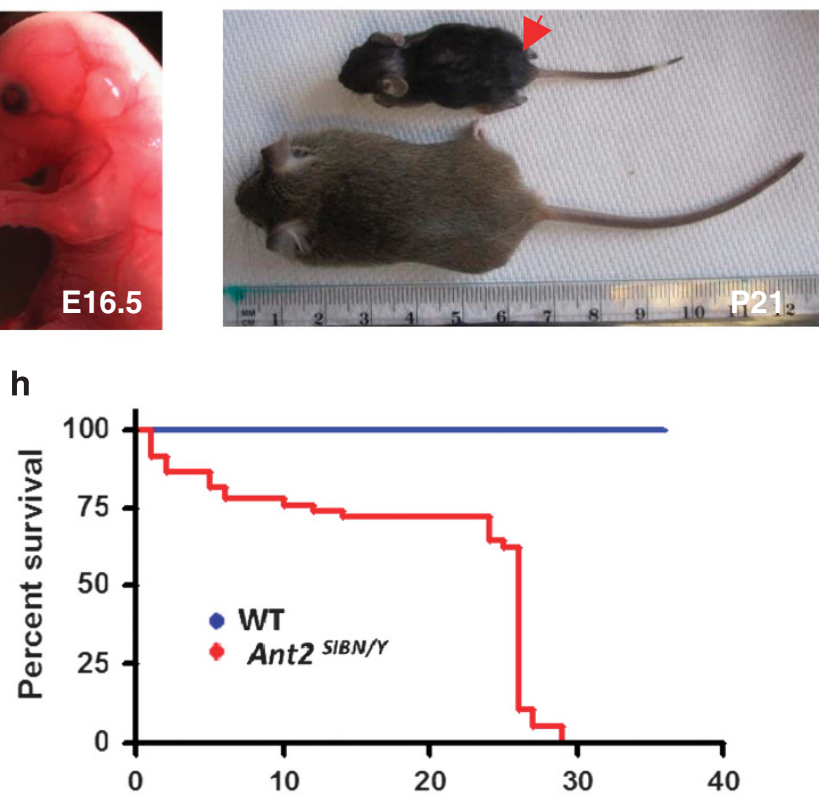
Table 1 Birth rate of Ant2 hypomorphic mice $(n=200)$

\begin{tabular}{|c|c|c|c|c|}
\hline & $+/+q$ & Ant2 ${ }^{S I B N /+}+$ & $+/ Y_{ठ}$ & Ant2 $2^{S I B N / Y}{ }^{\star}$ \\
\hline $\begin{array}{l}\text { Average number } \\
\text { of litters }\end{array}$ & $2.2 \pm 1.3$ & $2.1 \pm 1.2$ & $2.3 \pm 1.2$ & $0.9 \pm 0.9^{\star \star \star}$ \\
\hline Percent (\%) & $25.6 \pm 15.5$ & $27.7 \pm 13.8$ & $30.9 \pm 15.5$ & $12.9 \pm 12.4^{\star \star \star}$ \\
\hline
\end{tabular}

${ }^{\star \star \star} P<0.001$ as determined by the Student's t-test.

throughout the neonatal period, but all died within 4 weeks after birth (Figure 1h).

Expression of Ant1, Ant2 and Ant4 genes in Ant2 hypomorphic mice. As shown in Figure 2a, Ant2 mRNA expression was ubiquitously expressed in all the organs of WT animals as described previously. ${ }^{13}$ Ant2 mRNA expression was markedly decreased in all the organs examined from Ant $2^{S I B N / Y}$ mice. In contrast, Ant1 was particularly highly expressed in the heart and skeletal muscle as described previously $^{6}$ (Figure 2b). Small but significant compensatory increases in Ant1 expression were seen in some organs of Ant2 ${ }^{S I B N / Y}$ mice including the liver and kidney. Ant4 is known to be repressed in all the somatic organs of WT mice ${ }^{14}$ and was undetectable except in the testis of the $A n t 2^{S I B N / Y}$ mice (Figure 2c). In immunoblot analysis, Ant2 protein expression was undetectable in all the organs of $A n t 2^{\operatorname{SIBN} / Y}$ mice investigated. Small compensatory increases in Ant1 protein expression were seen in the Ant2 $2^{S I B N / Y}$ liver and kidney (Figure 2d).

Ant2 depletion induces anemia by maturation arrest of erythroid precursors. As the pale phenotype observed in Ant2 ${ }^{S I B N / Y}$ mice implies anemia, peripheral blood (PB) cell counts demonstrated that the neonatal Ant2 $2^{S I B N / Y}$ mice had macrocytic anemia (Figure 3a). The number of lymphocytes was reduced too, but those of platelets, neutrophils and monocytes were not significantly altered. The PB smears demonstrated a polychromasia, anisocytosis, poikilocytosis and increased number of large basophilic reticulocytes compared with WT littermates (Figure 3b). To further examine erythrocyte development, we performed flow cytometric analysis of erythroid precursors in BM. The orthochromatophilic erythroblast population was significantly decreased in Ant2 ${ }^{\text {SIBN/Y }}$ mice (Figure 4a). As seen with ANT1-depleted skeletal and cardiac muscles, ${ }^{23}$ Ant2 depletion caused increases in mitochondrial reactive oxygen species (ROS) levels in erythroid progenitors (Figure 4b). Further increases in cell death were also observed in basophilic and chromatophlic erythroblasts. Notably, among this dying cell population, Annexin $\mathrm{V}-$ and $7 \mathrm{AAD}+$ (7-aminoactinomycin D-positive) cells were predominant, suggesting that a large proportion of cells likely died via a non-apoptotic pathway (Figure 4c and Supplementary Figure S4).

Ant2 depletion induces B lymphocytopenia by decreased progenitors. To identify which types of lymphocytes are mostly affected, we stained BM, PB and spleen cells with $\mathrm{B} 220$ and $\mathrm{CD} 3$, for $\mathrm{B}$ and $\mathrm{T}$ cells, respectively. The B-lymphocyte population was consistently reduced in all of the Ant2-depleted organs. B220+ population in the spleen was less than one-third of WT, while T-cell population was relatively increased in both $B M$ and $P B$ compared with WT (Figure 5a). The number of pro-B and pre-B cells in BM as well as immature and mature $B$ cells in the spleen was lower in $A n t 2^{S I B N / Y}$ mice (Figure 5b). These B-cell progenitors and whole splenocytes demonstrated increases in ROS (Figure $5 c$ and d), which was accompanied by increases in cell death (Figure $5 \mathrm{~d}$ and Supplementary Figure S5). In contrast to B-cell development, T-cell development was apparently normal in the Ant2 $2^{S I B N / Y}$ thymus. The characterized population using CD4 and CD8 markers in the thymus did not show any particular difference in $A n t 2^{S I B N / Y}$ mice (Supplementary Figure S6A). In addition, there was no increase in ROS or cell death detected in Ant2-depleted thymocytes when compared with WT (Figure 6a and Supplementary Figure S6B). Increase in catalase was observed only in Ant2-depleted splenocytes but not in thymocytes, which was likely due to compensatory responses to increased ROS (Figure 6b).

To further investigate the type of cell death in Ant2-depleted splenocytes, we examined cleavage of caspase and poly ADP ribose polymerase (PARP), as well as DNA fragmentation. There were no overt increases in cleaved forms of PARP and caspase-3 in either the spleen or thymus (Figure 6c), whereas terminal deoxynucleotidyl transferase-mediated dUTP nickend labeling (TUNEL)-positive cells were increased only in the spleen (Figure 6d). As Ants have been implicated in the regulation of $\mathrm{mPTP},{ }^{24}$ we then evaluated $\mathrm{mPTP}$ opening in $\mathrm{B}$ and $T$ cells through cobalt-mediated calcein $A M$ elimination. Ant2-depleted splenic B cells showed a marked increase in cell population with reduction of calcein AM staining, indicating the mitochondrial pore opening. Pretreatment of cells with cyclosporin A (CsA) did not significantly decrease calcein AM low population. In contrast, Ant2 depletion did not affect calcein AM staining in thymic T cells (Figure 6e). These results taken together suggest that Ant2 depletion-mediated B-cell death accompanying MPTP opening is not likely through a typical apoptotic pathway.

To examine why $B$ and $T$ lymphocytes were differentially affected by Ant2 depletion, we investigated whether Ant1 and Ant2 expression levels and/or ratio are different in these cell populations. The mRNA levels and the ratio of Ant1 and Ant2 transcription in isolated $B$ cells and $T$ cells were largely similar (Figure 6f). Ant1 protein was not detectable in spleen and thymus in WT animals and there was no compensatory increase in Ant2-depleted organs. Ant2 protein expression level was also similar in both the spleen and thymus of WT animals, which were undetectable in $A n t 2^{S I B N / Y}$ organs (Figure $6 \mathrm{~g}$ ). These data indicate that a higher susceptibility in B lymphocytes to Ant2 depletion is not likely due to a differential expression of Ant1 and Ant2 between B and T cells.

Effects of Ant2 depletion on mitochondrial function. We next explored effects of Ant2 depletion on mitochondrial function. First, serum lactate levels were significantly higher in the Ant2 $2^{S I B N / Y}$ mice, which was consistent with a predicted mitochondrial respiratory defect phenotype. In Ant2-depleted splenocytes, basal extracellular acidification rate (ECAR) was increased, indicating upregulated glycolytic metabolism (Figure 7a). Although basal oxygen consumption rate (OCR) was similar between WT and Ant2 ${ }^{S I B N / Y}$ splenocytes, 
a

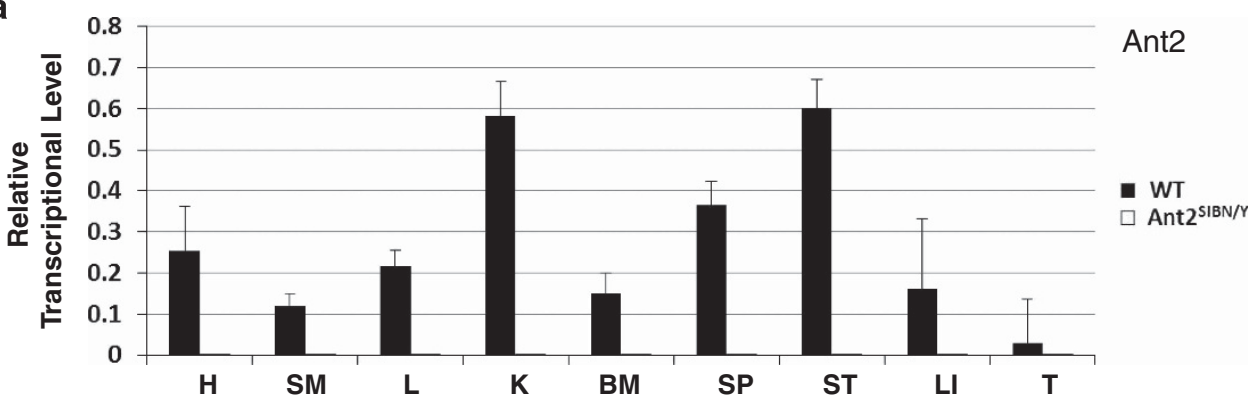

b
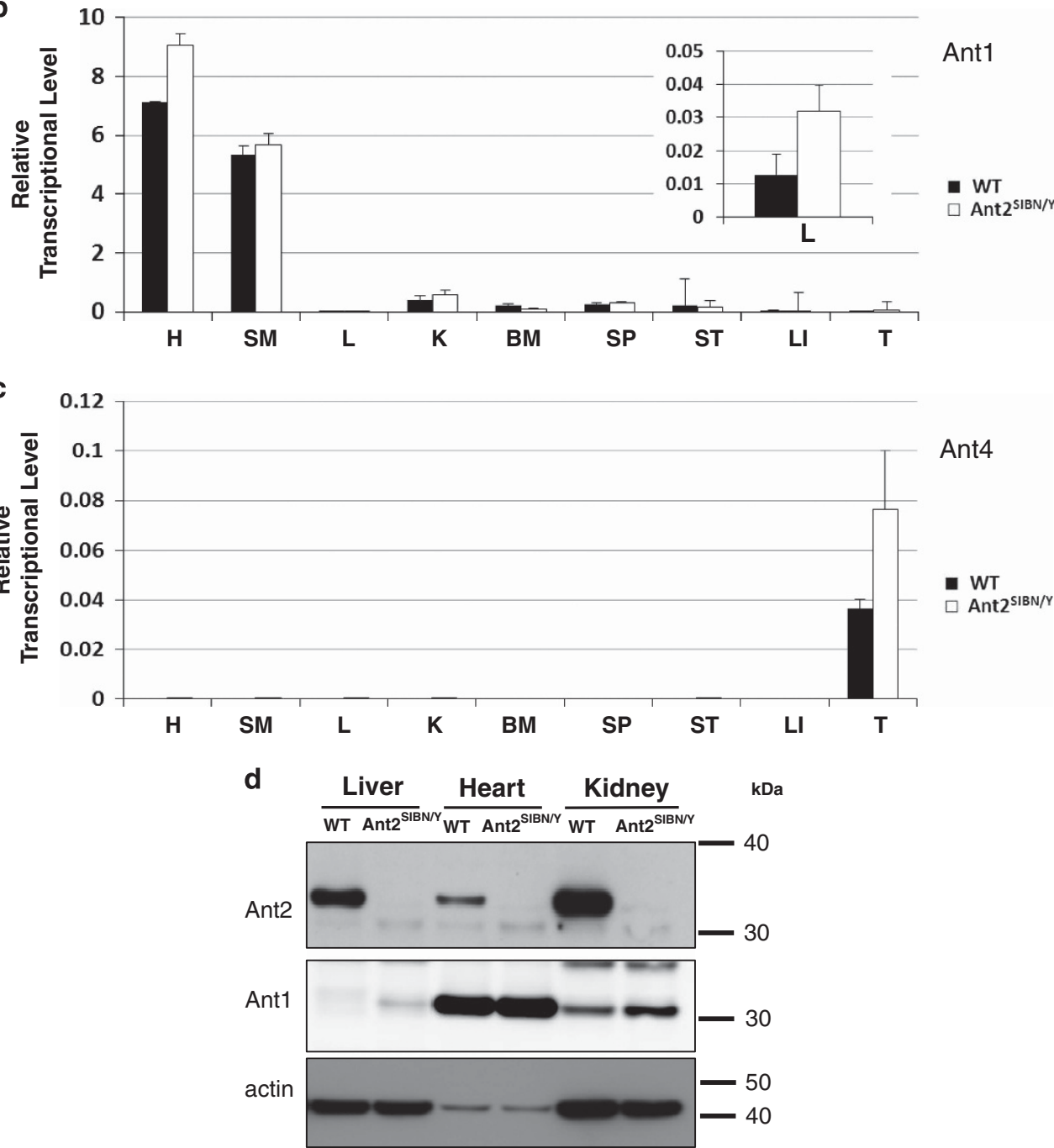

Figure 2 Ant isoform expression in WT and Ant2 hypomorphic mice. (a-c) mRNA expression of Ant2 (a), Ant1 (b) and Ant4 (c) in each organ of WT (Ant2 ${ }^{X Y}$ ) and Ant2 hypomorphic $\left(A n t 2^{S / B N / Y}\right.$ ) mice were evaluated by quantitative quantitative reverse transcription-PCR (RT-PCR). Each tissue was collected from P17 to P20 male littermates. Relative expression values of Ant genes to $\beta$-actin are shown using comparative $\Delta \mathrm{Ct}$ method. Error bars indicate S.D. (d) Protein expression levels of Ant2, Ant1 and $\beta$-actin were evaluated by immunoblotting. Predicted sizes for Ant1 and Ant2: 32kDa; $\beta$-actin: $42 \mathrm{kDa}$. H, heart; K, kidney; L, liver; LI, large intestine; SM, skeletal muscle; SP, spleen; ST, stomach; T, testis

maximal OCR after fluoro-carbonyl cyanide phenylhydrazone (FCCP) treatment was reduced by Ant2 depletion, indicating that the respiratory capacity was lower in the $A n t 2^{S I B N / Y}$ splenocytes. In contrast, Ant2 depletion did not affect ECAR or OCR in thymocytes (Figures $7 a$ and b). Mitochondrial membrane potential was then measured by tetramethyl rhodamine methyl ester (TMRM) staining. In parallel to MPTP opening shown above, Ant2 depletion increased the hypopolarized B cell population in spleen but has less effect in thymic $T$ cells (Figure 7c). Consistent with decreases in respiratory capacity, cellular ATP levels were lower in Ant2depleted splenocytes (Figure 7d), suggesting that increased 
a
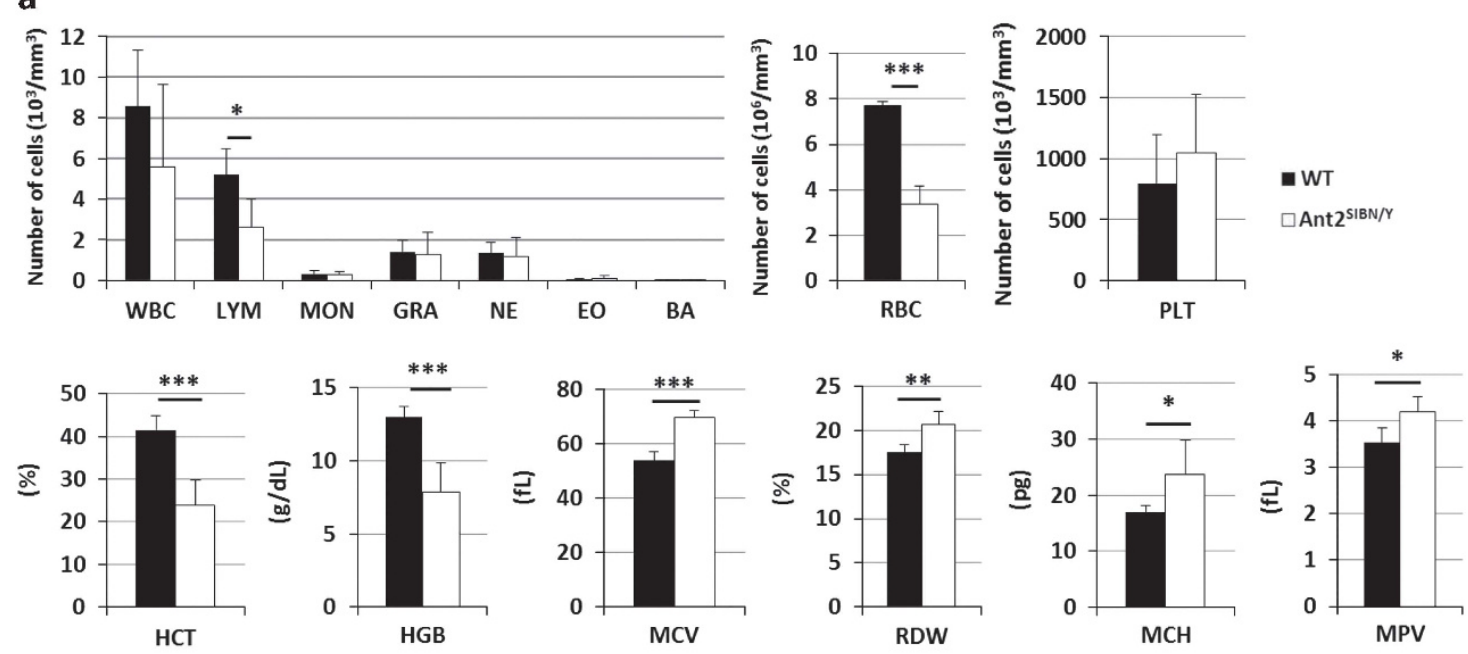

b

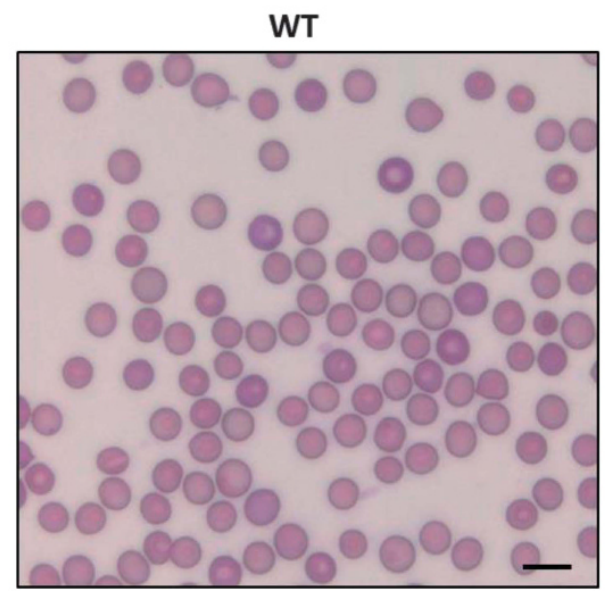

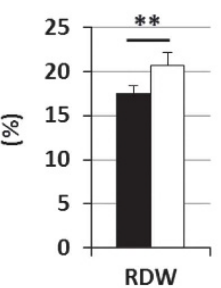
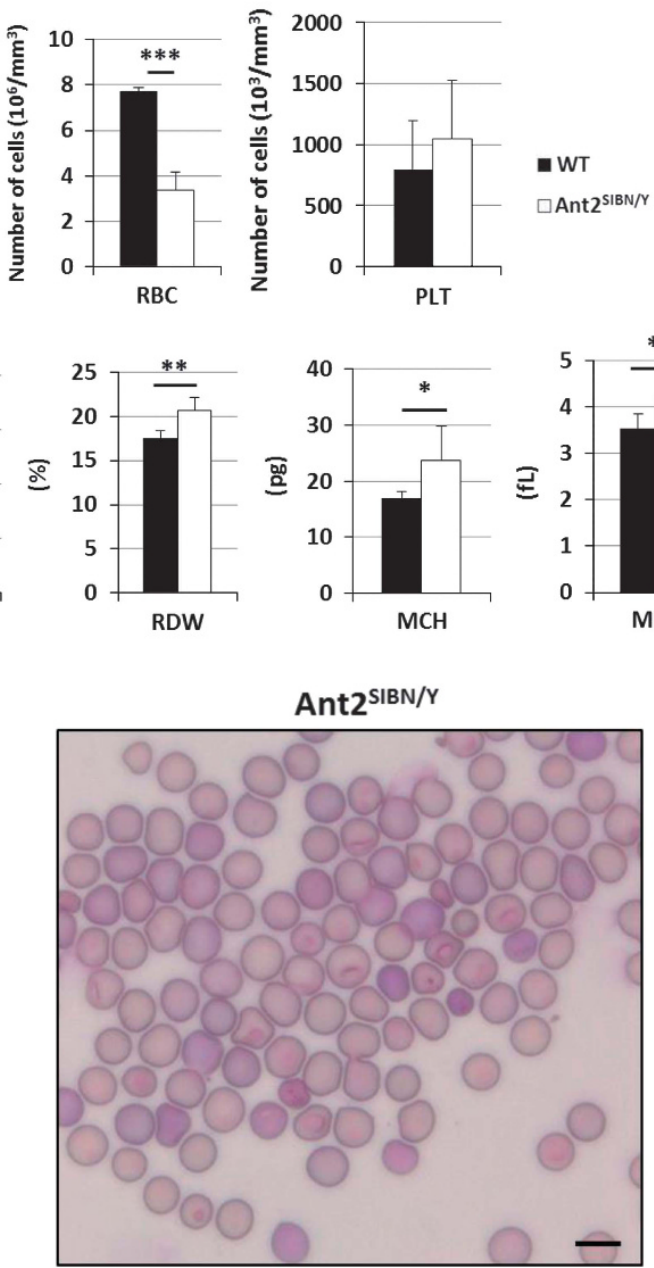

Figure 3 PB analyses in Ant2 hypomorphic mice. (a) Complete blood count (CBC) analyses in Ant2 hypomorphic mice at from P17 to P21 demonstrated reduced number of lymphocytes (LYM) and RBCs with decreased HGB concentration and HCT. Increased RDW, MCV and mean corpuscular hemoglobin (MCH) indicated macrocytic anemia (WT, $n=5$; Ant2 ${ }^{S I B N / Y}, n=6$ ). Error bars indicate S.D. $\left({ }^{*} P<0.05 ;{ }^{* *} P<0.01 ;{ }^{* * \star} P<0.001\right.$ as determined by the Student's $t$-test). (b) Blood smear analyses displayed target cells and macrocytic anemia. Scale bar: $10 \mu \mathrm{m}$. BA, basophil; EO, eosinophil; GRA, granulocytes; MON, monocytes; NE, neutrophil; PLT, platelet; WBC, white blood cells

glycolysis is not sufficient for compensation. In contrast to the previous report of effects of Ant1 depletion in heart and skeletal muscle, ${ }^{23}$ the mitochondrial deoxyribonucleic acid (mtDNA) copy numbers in $A n t 2^{S I B N / Y}$ spleens were rather reduced (Figure $7 \mathrm{e}$ ), and we did not see an increase in mitochondrial number either at electron microscopic analysis of the spleen (Figure 7f). These data indicate there was no obvious compensatory mitochondrial proliferation in the Ant2-depleted spleens. Further, the ratio of cytosolic LC3-I/II was not altered by Ant2 depletion (Figure 7g), indicating autophagy, another compensatory response to damaged mitochondria, was not increased either.

Effects of Ant2 depletion on hematopoietic stem/progenitor cell function. As increases in ROS were seen in the earliest erythroid and B-lineage precursors investigated, we further explored hematopoietic stem cells and precursors in BM. As shown in Figure 8a, Ant2-depleted BM exhibited an increase in lineage-negative (Lin - ) cell frequency while having a similar frequency of Lin -, Sca1+ and c-Kit+ (LSK) cells. Although the population of LSK cells was similar, Ant2 ${ }^{\text {SIBN/Y }}$ LSK cells demonstrated increased ROS levels, as seen in RBC and B-cell progenitor cells. In addition, BM cells in WT and $A n t 2^{S I B N / Y}$ animal had a similar CFU-GM (colonyforming unit-granulocyte macrophage) activity, whereas Ant2 ${ }^{S I B N / Y}$ mice demonstrated increased CFU-E (colonyforming unit-erythroid) colonies (Figure 8b). As the pale phenotype was observed in embryonic stages, we also investigated embryonic hematopoiesis by performing the colony assays using fetal liver (FL) cells from WT and Ant $2^{S I B N / Y}$ animals. As seen in BM cells, Ant2-depleted FL showed similar numbers in CFU-GM but increased CFU-E (WT versus Ant $2^{\text {SIBN/Y }}$, CFU-GM $17 \pm 4$ versus $16 \pm 5, n=4$; CFU-E $24 \pm 3$ versus $36 \pm 4, n=4, P<0.001)$. These data indicate that despite elevated ROS, Ant2 ${ }^{S I B N / Y}$ mice have intact or rather increased hematopoietic stem/precursor cells including erythroid lineage stem cells.

Hematopoietic phenotypes were recapitulated after transplantation of Ant2-depleted BM. To test if Ant2 
a
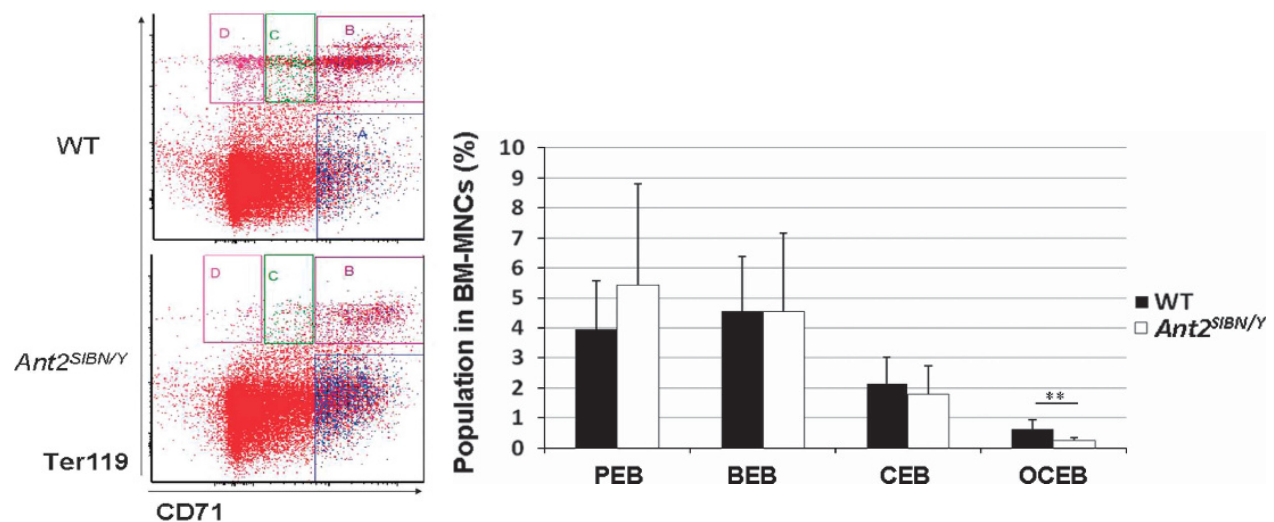

b

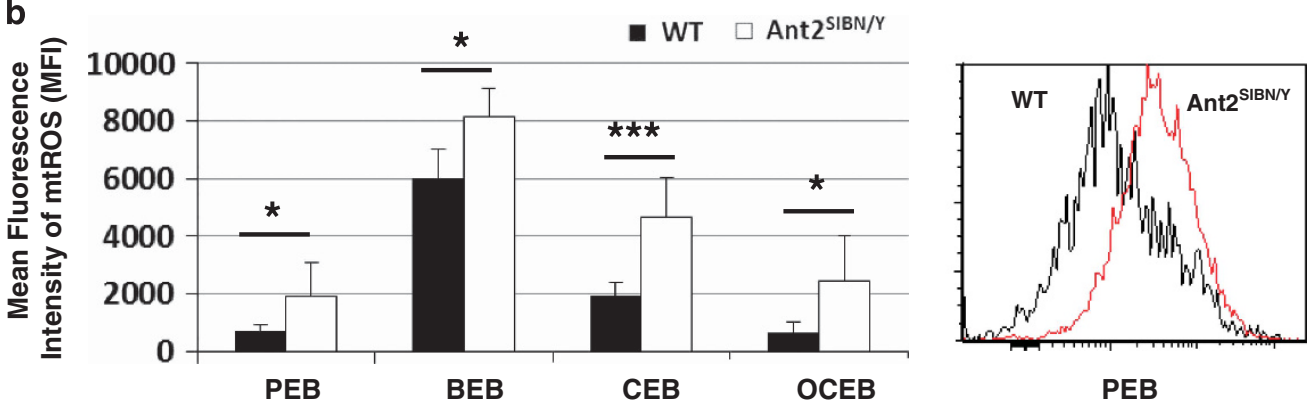

C

BEB

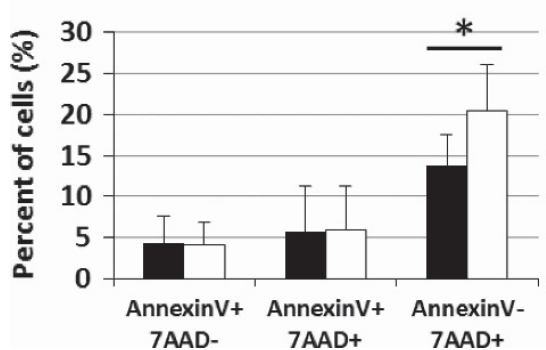

CEB

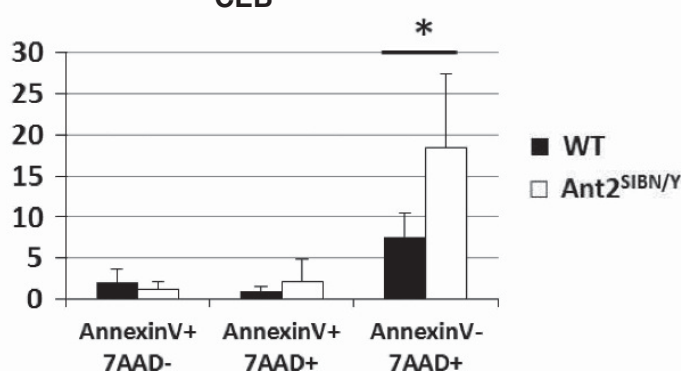

Figure 4 Effects of Ant2 depletion on erythroid precursors. (a) BM cells were isolated from WT and Ant2 ${ }^{S I B N Y}$ mice (P17), and stained for Ter119 and CD71. Ter119 CD71 ${ }^{\text {high }}$, Ter119+CD71 ${ }^{\text {high }}$, Ter119+CD71 ${ }^{\text {med }}$ and Ter119+CD71 $1^{\text {low }}$ cells represent proerythroblast (PEB), basophilic erythroblast (BEB), chromatophilic erythroblast (CEB) and orthochromatophilic erythroblast (OCEB) population, respectively. The orthochromatophilic erythroblast population was significantly decreased (WT, $\left.n=8 ; A n 2^{S I B N / Y}, n=7\right)$. (b) Mitochondrial ROS was increased in all the erythroid precursors investigated in $A n t 2^{S B N / Y}$ mice $\left(\mathrm{WT}, n=4 ; A n t 2^{S B N / Y}, n=4\right)$. A representative histogram is shown for PEB cells (right). (c) Cell death was assessed by flow cytometry analysis of 7AAD and Annexin V. BEB population in Ant2 $2^{S B N / Y}$ mice demonstrated an increase in the 7AAD+, Annexin $\mathrm{V}$ - population (WT $=4$; Ant2 $\left.{ }^{S I B N Y}, n=4\right)$. Error bars indicate S.D. $\left({ }^{\star} P<0.05 ;{ }^{* \star} P<0.01 ;{ }^{* \star} P<0.001\right.$ as determined by the Student's $t$-test)

depletion leads to hematopoietic phenotypes in a cellautonomous manner, we performed BM transplantation experiments. BM cells from WT and $A n t 2^{S I B N / Y}$ mice were transplanted into lethally irradiated recipient mice. A month later, we assessed $\mathrm{PB}$ in the recipient mice. Although milder compared with the original $A n t 2^{S I B N / Y}$ mice, most of the blood phenotypes were recapitulated in the recipient animals (Figure 8c). Notably, a significant reduction in the number of RBCs, and lymphocytes, hematocrit (HCT) level and hemoglobin (HGB), as well as increased mean corpuscular volume (MCV) and red blood cell distribution width (RDW), were observed in the mice receiving $A n t 2^{S I B N / Y}$ BM cells. When we investigated the number of $T$ cells and $B$ cells in $P B$ after 1 month of transplantation, only $B$ cells were decreased in the mice receiving Ant2 ${ }^{S I B N / Y}$ BM cells (Figure $8 d$ ).

\section{Discussion}

Based on the phenotypes seen in the Ant1 and Ant4 knockout mice, and the ubiquitous expression profile of Ant2, we speculated that depletion of Ant2 lead to severe consequence in almost all organ systems, accompanied by decreased bioenergetics and increased oxygen radicals. Indeed, Ant2depleted mice showed severe postnatal growth retardation with lactic acidosis, consistent with the predicted phenotype due to general mitochondrial dysfunction. However, by closer look, only limited organs and cell types were primarily affected by Ant2 depletion, including cells of the hematopoietic system and GI tract. The present study indicates that Ant2 is largely dispensable in many organs at least during early embryonic development. Even with a complete disruption of the Ant2 gene $\left(A n t 2^{1 f / Y}\right)$, the embryos developed until E12.5 to E14.5 
a

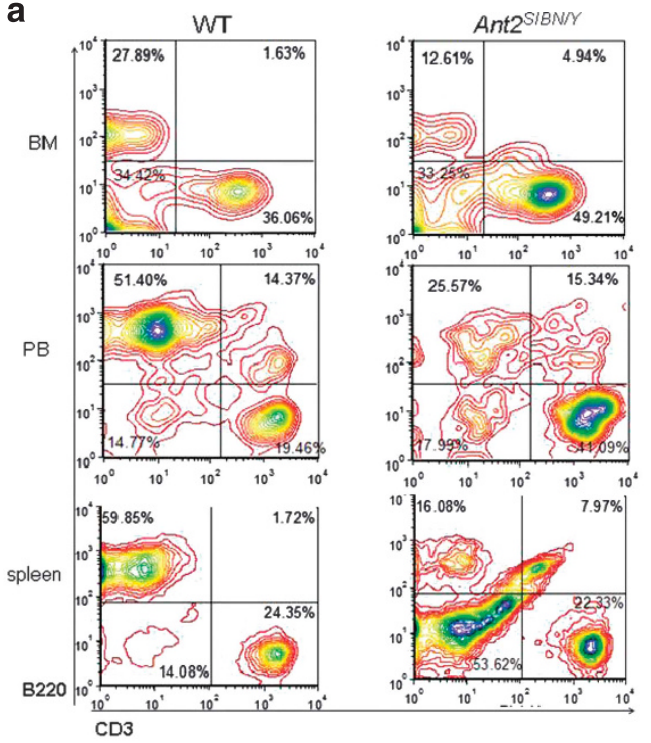

b
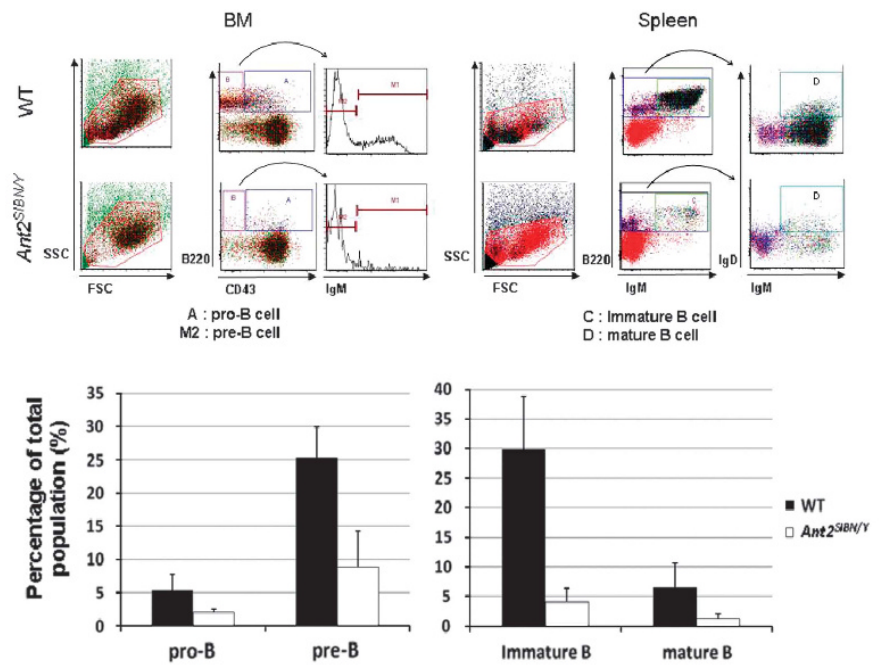

C

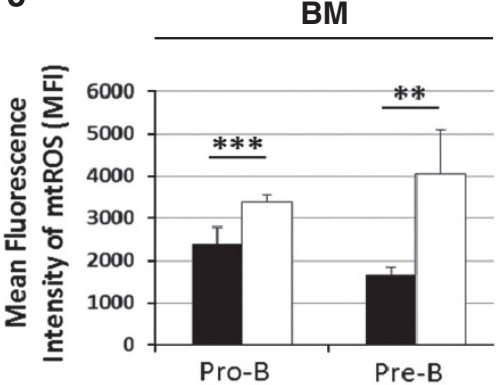

spleen

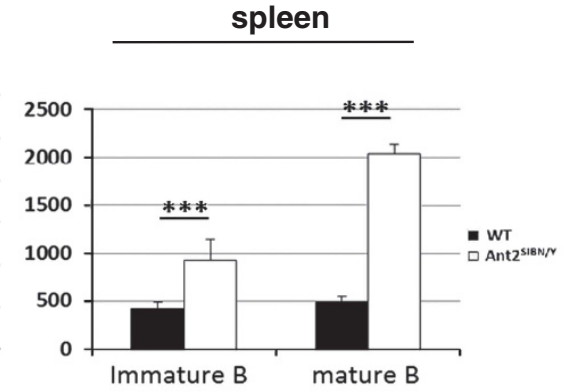

d

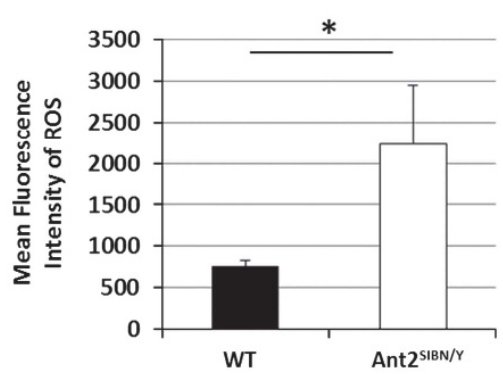

e

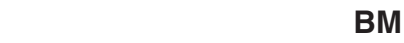

BM

spleen
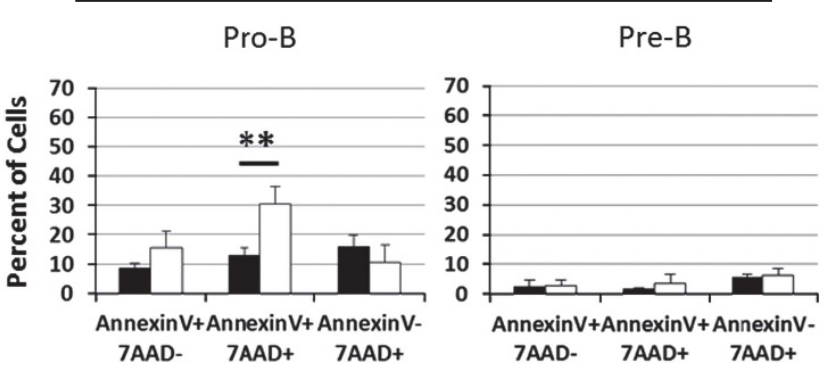

Pre-B

Immature B

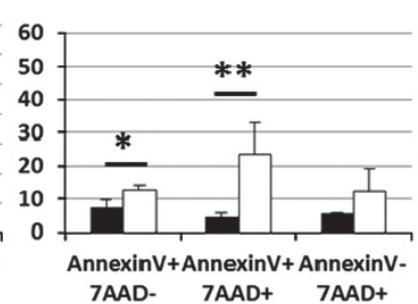

mature $\mathrm{B}$

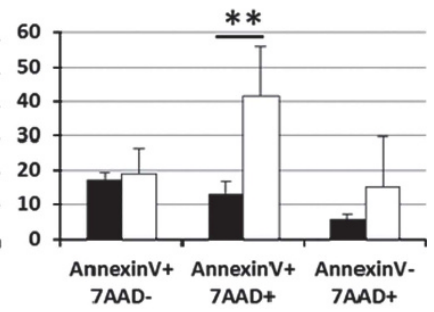

Figure 5 Effects of Ant2 depletion on B-lymphocyte precursors. (a) B- and T-lymphocyte ratio in BM, PB and spleen were determined by flow cytometry using anti-B220 and anti-CD3 antibodies. $B$ lymphocytes were decreased in all hematopoietic organs of $A n t 2^{S / B N / Y}$ mice (P17), whereas $C D 3+$ cells remained relatively high or similar. The figure shows a representative of three similar results. (b) BM cells or spleen cells (P17) were subjected to flow cytometry for separation of progenitor B cells (B220+, CD43+), precursor

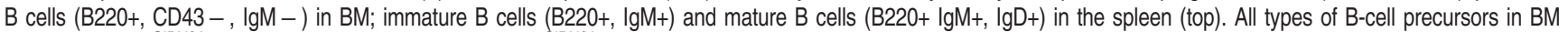
(WT, $n=8$; Ant2 ${ }^{S I B N Y}, n=11$ ) and spleen (WT, $n=11 ; A n 2^{S I B N / Y}, n=14$ ) were significantly reduced (bottom). (c) Mitochondrial ROS was elevated in progenitor and precursor

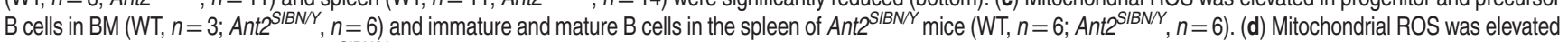
in whole splenocytes (WT, $n=6$; Ant2 ${ }^{S I B N Y Y}, n=6$ ). (e) Cell death was assessed by flow cytometry analysis of 7AAD and Annexin V. Ant2 depletion increased 7AAD+, Annexin V+ cell population in all B-cell precursors except for pre-B cells in BM (WT, $n=3$; Ant2 $\left.{ }^{S B N / Y}, n=3\right)$ and spleen $\left(W T, n=3 ;\right.$ Ant $\left.2^{S I B N Y}, n=3\right)$. Error bars indicate S.D. $\left({ }^{\star} P<0.05\right.$; ${ }^{* *} P<0.01 ;{ }^{* * *} P<0.001$ as determined by the Student's $t$-test or analysis of variance (ANOVA))

with no apparent gross anatomical defect except a pale phenotype (Supplementary Figure S7).

There was no clear correlation detected between organ susceptibility and levels of Ant2 expression in WT mice. Unlike in Ant1 knockout mice, the organs highly expressing Ant2 were not necessarily affected by the depletion. As such, the kidney, which expresses the highest level of Ant2, was apparently unaffected within a month after birth. Indeed, blood urea nitrogen and creatinine levels were within normal ranges in the mutant mice at P21 (data not shown), suggesting that Ant2 depletion does not cause immediate renal dysfunction. The liver also appeared intact at the macroscopic and morphological levels, despite this organ showing the highest expression ratio between Ant2 and Ant1, and a 
a

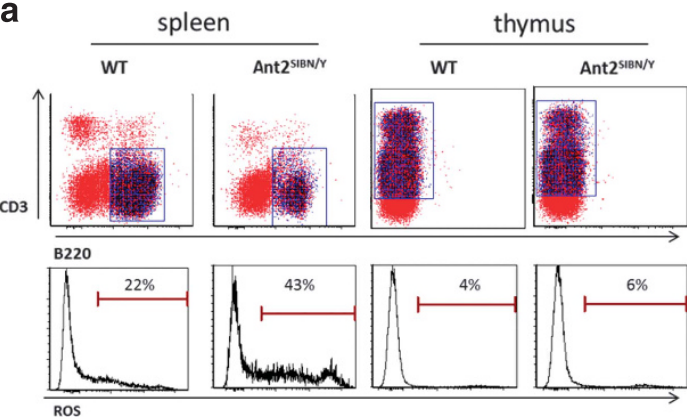

C

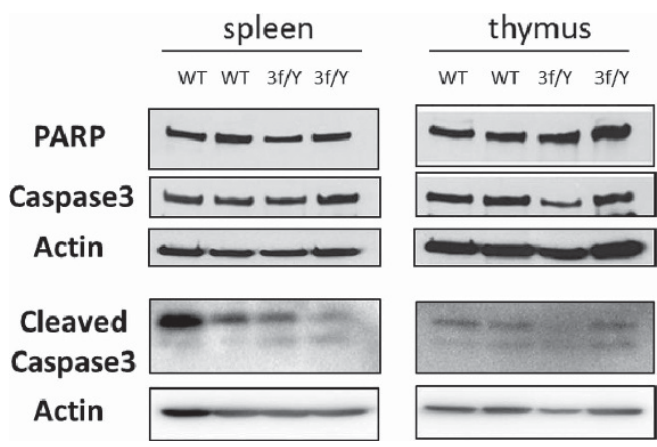

e

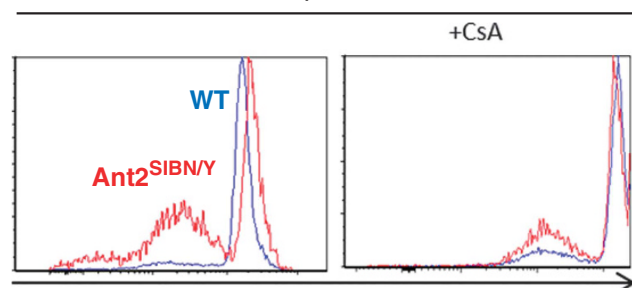

Calcein-AM

f

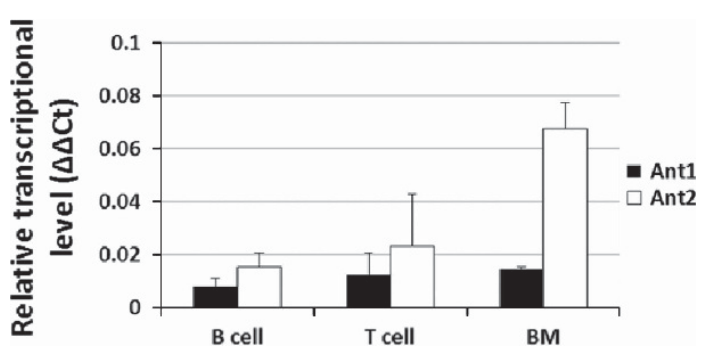

b

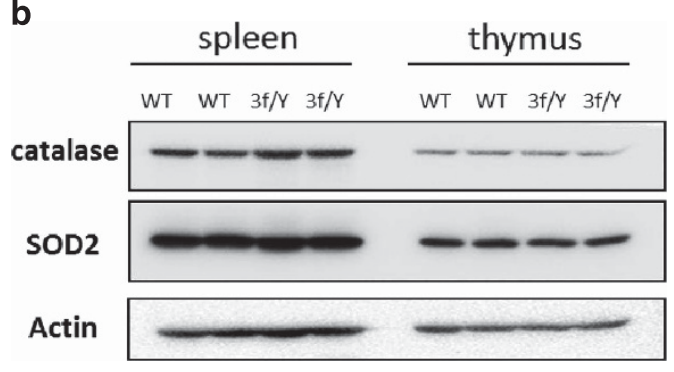

d
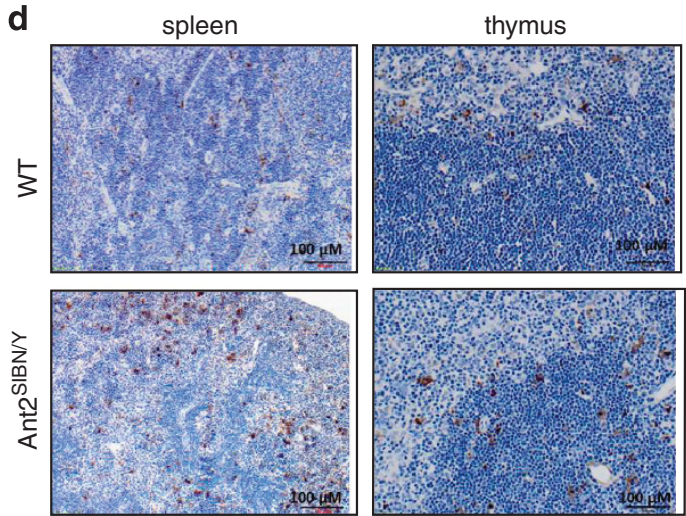

thymus

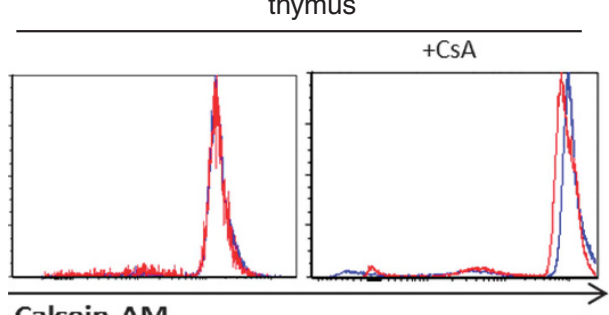

Calcein-AM

g

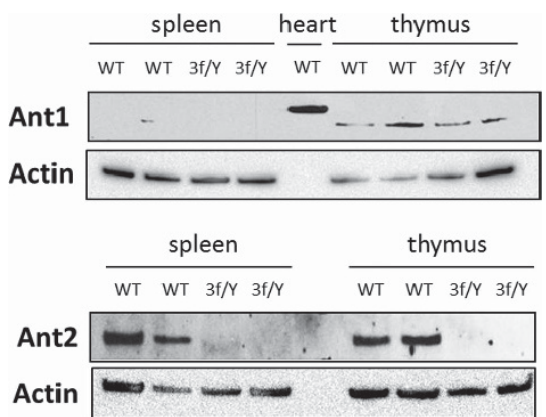

Figure 6 Comparison of ROS and cell death in Ant2-depleted spleen and thymus. (a) Mitochondrial ROS in B and T lymphocytes (B220+ and CD3+ cells in the spleen and thymus, respectively) was determined by flow cytometry. ROS in B lymphocytes but not in T lymphocytes was increased. Representative diagram of three to five similar results is presented. (b) Protein expression levels of antioxidant enzymes in WT and Ant2-depleted spleen and thymus were measured by immunoblot. The amount of catalase was increased in Ant2-depleted spleen. (c) Protein levels of PARP, caspase-3 and cleaved caspase-3 were detected by immunoblot. (d) DNA fragmentation was detected by TUNEL assay. TUNEL+ cells were increased in Ant2-depleted spleen compared with WT. (e) mPTP in B and T cells (B220+ and CD3+ cells in the spleen and thymus, respectively) was assessed by flow cytometry with calcein $\mathrm{AM}$ and $\mathrm{CoCl}_{2}$ staining under $\mathrm{CsA}$-treated or -untreated conditions. $\mathrm{Pl}+$ cells were excluded before measuring calcein $\mathrm{AM}$. A representative diagram of three independent experiments is presented here. (f) Ant1 and Ant2 mRNA expression levels were measured by quantitative quantitative reverse transcription-PCR (RT-PCR) with sorted B cells (B220+), T cells (CD3+) from BM, and whole BM cells in WT mice. Relative expression levels of Ant2 or Ant1 gene to $\beta$-actin using the comparative $\Delta$ Ct method are shown. (g) Immunoblot analysis of Ant1 and Ant2. Heart sample was loaded as a positive control for Ant1. 3f/Y indicates Ant2 ${ }^{S / B N / Y}$. Error bars indicate S.D. 

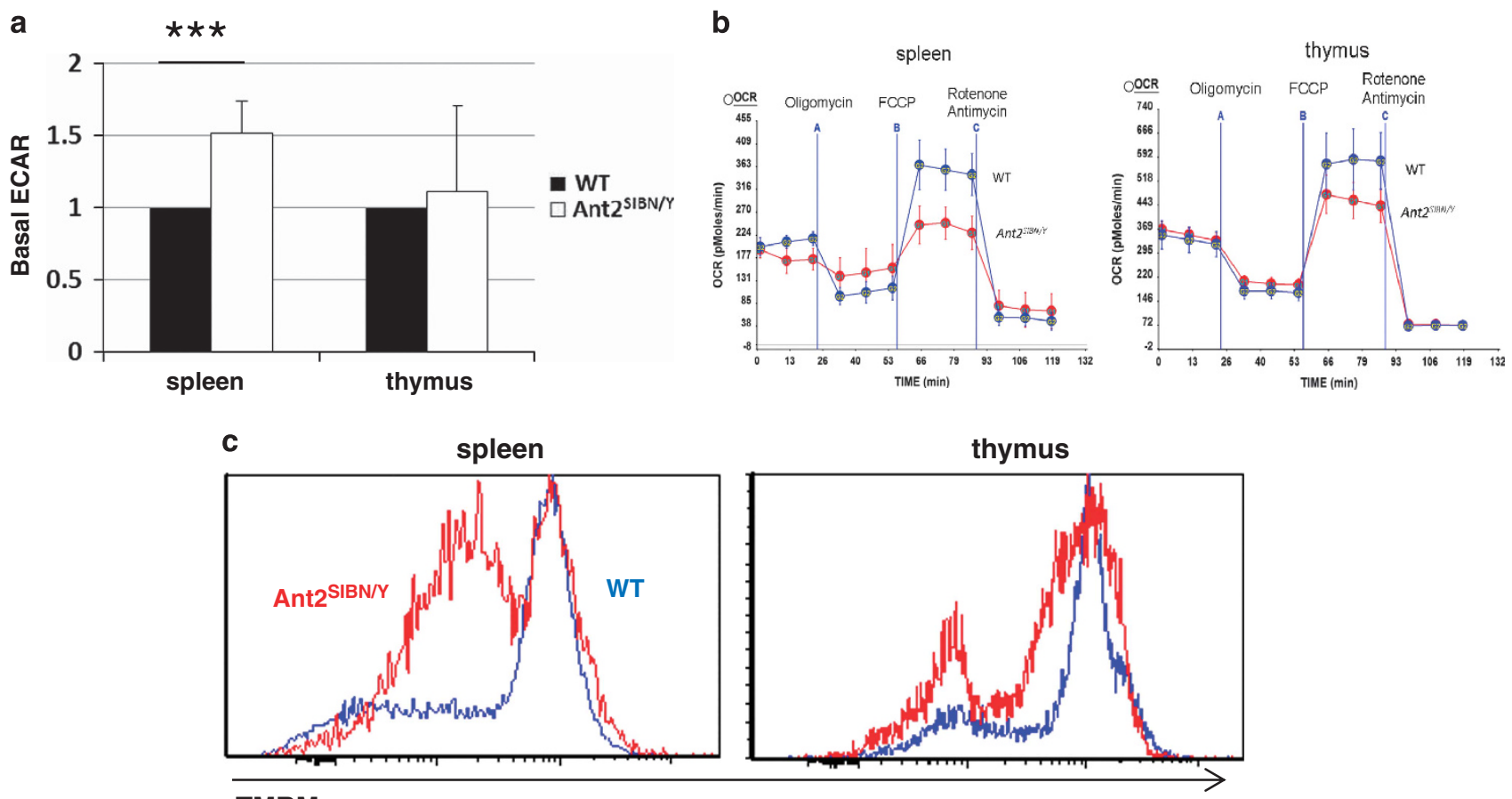

TMRM

d

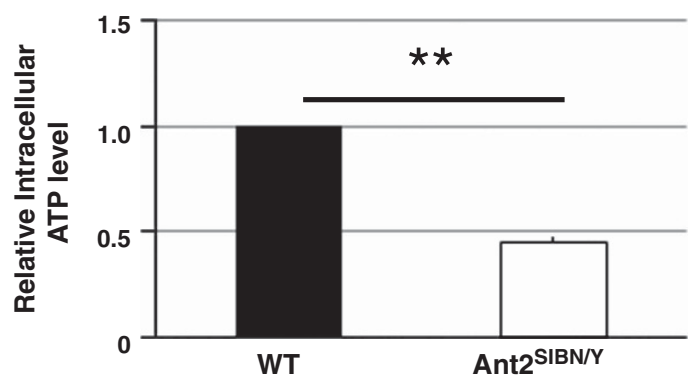

e

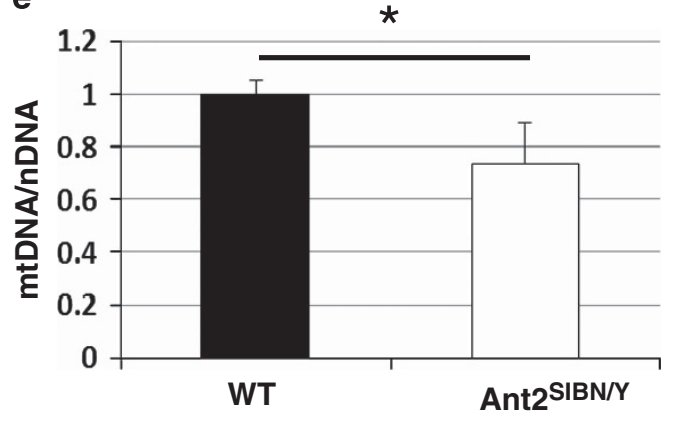

f

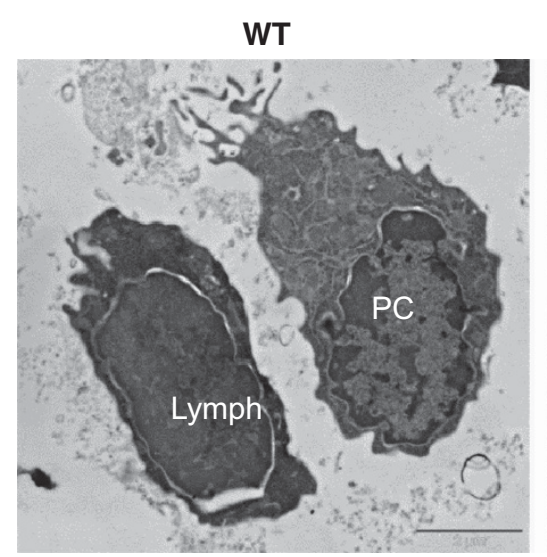

Ant2 ${ }^{\mathrm{SIBN} / \mathrm{Y}}$

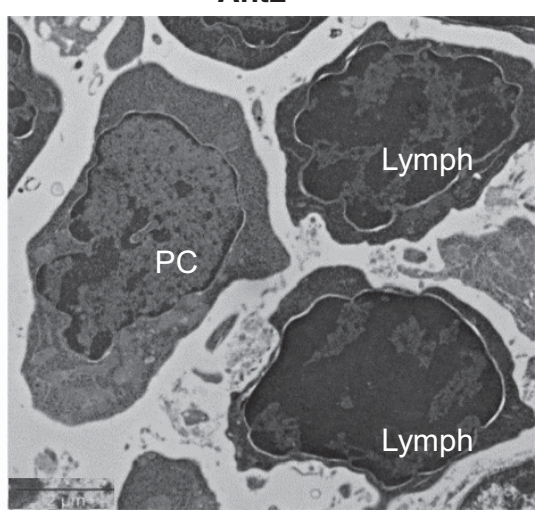

g

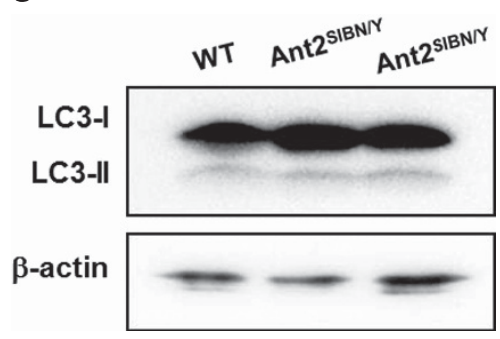

Figure 7 Mitochondrial dysfunction in Ant2 hypomorphic spleen. (a) Basal ECAR was significantly increased in Ant2 ${ }^{S / B N /}$ splenocytes but not in thymocytes (P14-17) (WT, $n=3$; Ant2 ${ }^{S I B N / Y}, n=6$ ). (b) OCRs in splenocytes and thymocytes in WT and Ant2 ${ }^{S B B N / Y}$ animal in response to $1 \mu \mathrm{M}$ oligomycin, $1 \mu \mathrm{M}$ FCCP and $1 \mu \mathrm{M}$ antimycin A and $1 \mu \mathrm{M}$ rotenone. Maximum respiration rate was decreased in $A n t 2^{2 S N N / Y}$ spleen (WT, $n=4$; Ant2 $\left.{ }^{S / B N / Y}, n=4\right)$. (c) Mitochondrial membrane potential in B and T cells (B220+ and CD3+ cells in the spleen and thymus, respectively) were assessed by flow cytometry with TMRM staining. The hypopolarized cell population was increased in Ant2-depleted B cells (WT, $\left.n=4 ; A_{n t 2}^{S I B N Y}, n=4\right)$. (d) Relative intracellular ATP levels were decreased in splenocytes (WT, $\left.n=5 ; A^{\prime} 2^{S I B N / Y}, n=4\right)$. (e) mtDNA copy number relative to nuclear DNA was decreased (WT, $n=4 ;$ Ant2 ${ }^{S I B N / Y}, n=4$ ) in splenocytes. (f) Transmission electron microscopy analyses of the spleen from P18 WTand Ant2 $2^{S B N N /}$ Ant2 hypomorphic mice. Scale bar: $2 \mu \mathrm{m}$. (g) Immunoblot analysis of cytoplasmic LC3-I and LC3-II in splenocytes. Error bars indicate S.D. $\left({ }^{*} P<0.05 ;{ }^{* *} P<0.01 ;{ }^{* *} P<0.001\right.$ as determined by the Student's t-test). PC, plasma cell; lymph, lymphocyte 
a
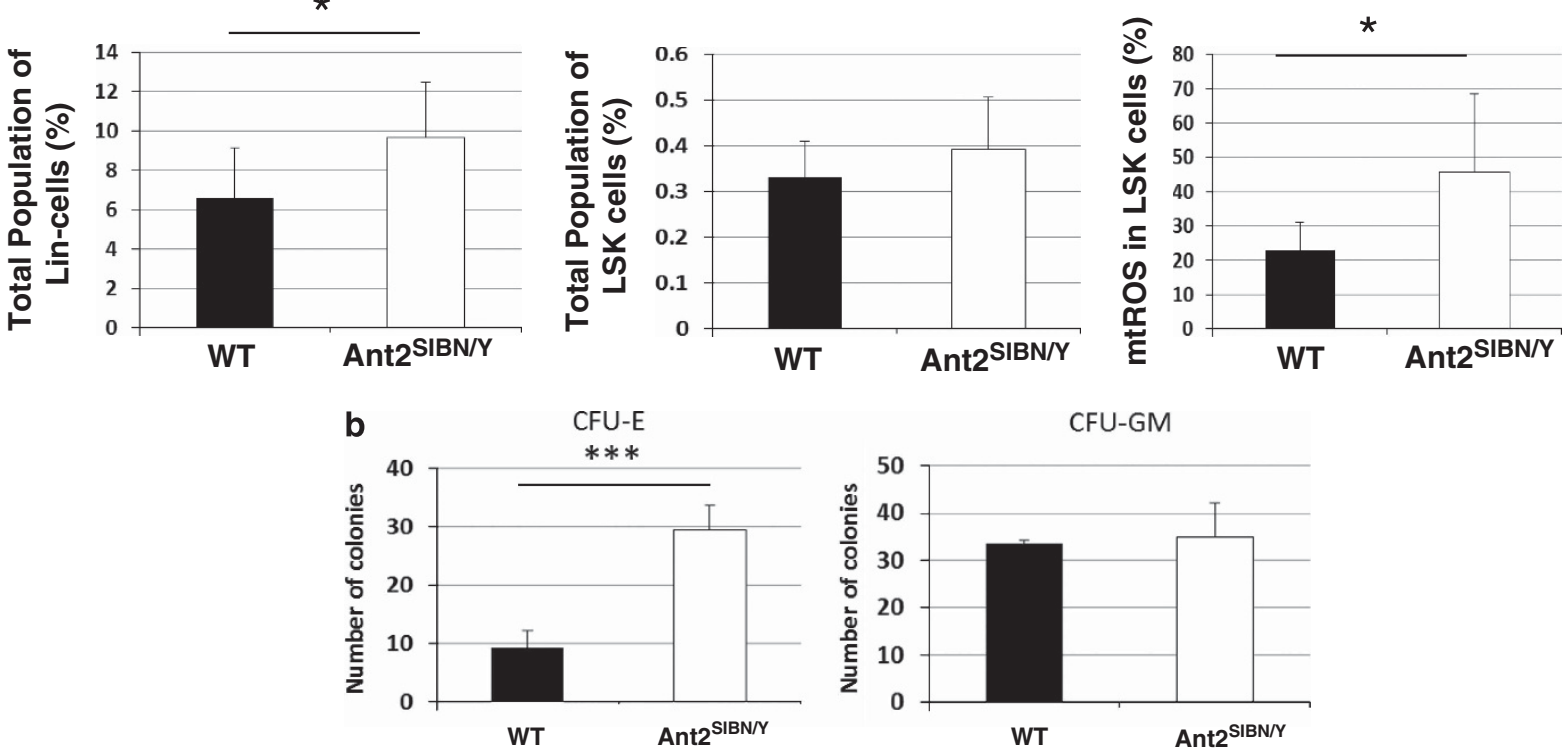

CFU-GM

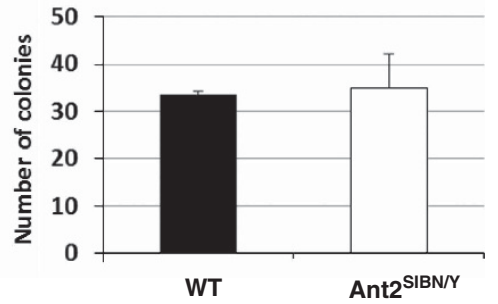

C
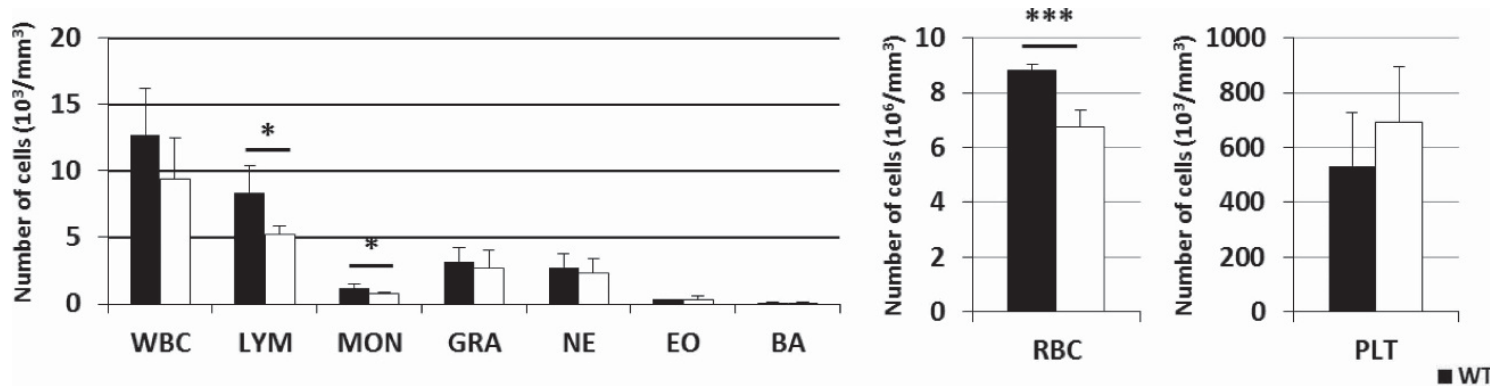

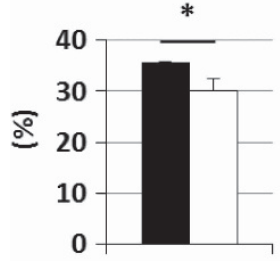

HCT

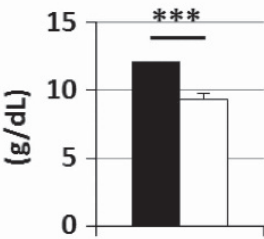

HGB

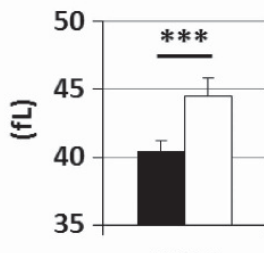

MCV
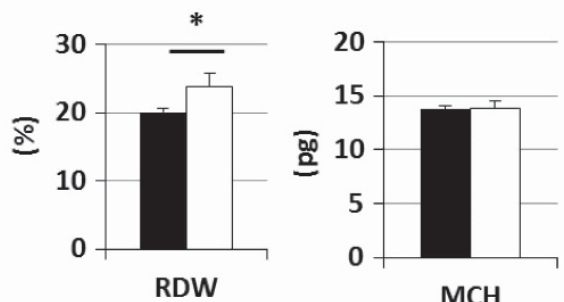

d

WT

Ant2 ${ }^{\text {SIBN/Y }}$
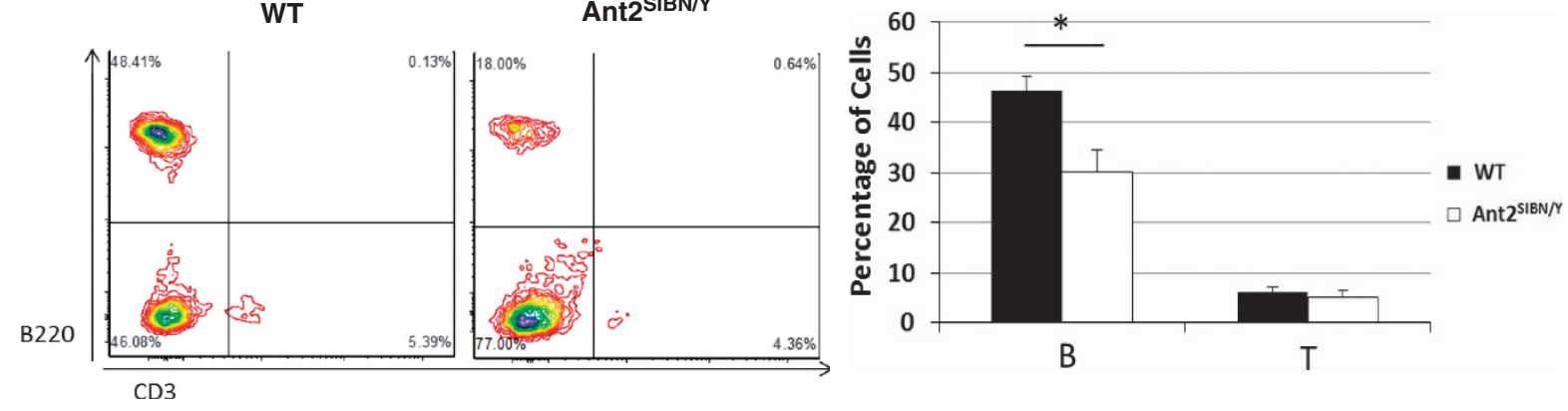

Figure 8 Evaluation of hematopoietic stem/progenitor cells and BM transplantation analyses. (a) Total population of Lin - cells (left) and LSK cells (middle) in WT and

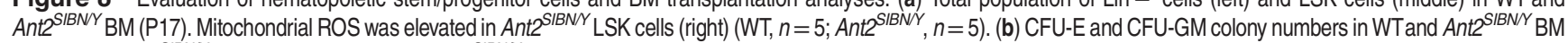
$\left(\mathrm{WT}, n=4 ;\right.$ Ant2 $\left.^{S / B N Y}, n=4\right)$. (c) Either WTor $A n 2^{S / B N / Y}$ BM (P17-19) was transplanted into lethally irradiated WT mice, and PB cells were analyzed 1 month later (WT, $n=2$; $\left.A n t 2^{S / B N / Y}, n=4\right)$. (d) B220+ and CD3+ cell ratio was analyzed in PB mononuclear cells after BM transplantation (WT, $n=2 ;$ Ant2 $\left.{ }^{S / B N / Y}, n=4\right)$. A representative diagram (left) and average numbers of triplicate experiments (right) are shown. Error bars indicate S.D. $\left({ }^{*} P<0.05 ;{ }^{* \star \star} P<0.001\right.$ as determined by the Student's $t$-test or analysis of variance (ANOVA)) 
hepatoprotective effect of Ant2 being indicated. ${ }^{25}$ Our data were consistent with the previous report, where they showed apparently normal liver development even without both Ant1 and $A n t 2 .^{21}$ These data imply that some organs are very tolerant to Ant2 depletion or even depletion of all mitochondrial ATP transporters described to date. It is however still unanswered whether these organs remain normal long term without Ant2, and if Ant2 may have some essential role in organ homeostasis.

Hematopoietic failure in the mutant mice appears to be one of the primary effects caused by Ant2 depletion. Of interest, erythroid and B-lymphocyte development was particularly impaired with little to no effect on myeloid, megakaryocyte or T-lymphocyte lineages. Although ROS was increased from the earliest common hematopoietic progenitor population we investigated, the phenotype was very limited to specific cell lineages. The hematopoietic failure phenotype caused by Ant2 depletion is not likely a secondary event due to malnutrition, as the anemic phenotype was observed even during embryonic stages when growth was apparently normal. Indeed, similar hematopoietic abnormalities were recapitulated, although to a milder extent, in irradiated mice reconstituted with Ant2depeleted BM cells. We still do not know the reason why $B$ cells are more susceptible than $\mathrm{T}$ cells to Ant2 depletion. Expression levels of compensatory Ant1 or ROS-scavenging enzymes including catalase and superoxide dismutase 2 (SOD2) were not higher in the thymus when compared with those in the spleen. B-lymphocyte development might require more oxidative respiration, while T-cell development may be more dependent on glycolytic energy metabolism. Alternatively, Ant2-interacting proteins such as Sirt4 ${ }^{26}$ and $\mathrm{Btg}^{27}$ could be differentially expressed or regulated in these cell populations. The roles of such proteins in Ant2 depletion-mediated cell death would be interesting subjects to explore.

It has been shown previously that general mitochondrial defects can cause hematopoietic failure in some model animals. ${ }^{28,29}$ Inoue et al. ${ }^{30}$ reported that large-scale mtDNA depletion in hematopoietic cells leads to failure in erythropoiesis and resultant macrocytic anemia, indicating that erythrocyte differentiation is susceptible to mitochondrial respiration defects. Further, Chen et al. ${ }^{31}$ reported that mtDNA polymerase $y$ (POLG) mutant mice developed a progressive and ultimately fatal megaloblastic anemia that was associated with both erythrodysplasia and impaired lymphopoiesis, similar to the phenotype of our Ant2-depleted mice. However, POLG mutant mice show a more pancytopenic problem in hematopoiesis, and Tand B lymphocytes are equally affected, in contrast to our Ant2-depleted mice. Mitochondrial quality control is exerted through fusion, fission and ultimately mitophagy to remove severely damaged mitochondria. Atg5 has a critical role in autophagy with proper conjugation of Atg12. ${ }^{32}$ Depletion of Atg5 caused increased cell death in pre-B cells followed by developmental defect of B lymphocytes while $\mathrm{T}$ lymphocytes underwent full maturation, ${ }^{33,34}$ a phenotype that is similar to our Ant2 hypomorphic mice. B-cell development and erythroid precursors may be particularly susceptible to accumulation of mitochondrial damages.

Severe postnatal growth retardation and failure to thrive is likely attributed to $\mathrm{Gl}$ tract abnormalities. The enlarged stomach filled with milk was observed without any downstream anatomical stenosis or obstruction, which indicates a functional obstruction of the upper GI tract exists. This would cause a failure to absorb nutrients during the neonatal period. GI tract problems have been occasionally reported in other patients and animal models with mitochondrial dysfunction. In particular, mitochondrial neurogastrointestinal encephalopathy (MNGIE) is an autosomal recessive disorder caused by mutation in the TYMP gene, which encodes thymidine phosphorylase (TP). TP dysfunction results in a systemic increase of thymidine in plasma and selectively impairs mtDNA replication and repair. ${ }^{35,36}$ Abnormalities of the digestive system are among the most common and severe features of MNGIE patients. The Gl dysmotility, in which the muscles and nerves of the digestive system do not move food through the digestive tract efficiently, is a typical condition of the disease. These GI problems lead to extreme weight loss and reduced muscle mass (cachexia). ${ }^{37,38}$ It is conceivable that similar functional defects could be involved in the Ant2 hypomorphic animals, and potential contribution of Ant2 mutations in clinical patients with gastroparesis should be a subject for future investigation.

Here, we report the generation of hypomorphic, conditional and null alleles of the Ant2 gene to delineate the role of ANT2 in development and postnatal life. Studies of spatiotemporal deletions of $A n t 2\left(A n t 2^{2 \pi}\right)$ with various Cre or CreER strains are warranted to further elucidate the role of Ant2 in specific cell types and time during development and postnatal life. Such mutant animals will be also very useful for biochemical analyses to define potential specific functions of $A N T$ paralogs in each organ.

\section{Materials and Methods}

Targeted disruption of Ant2 gene in mice. Mice were maintained under standard specific-pathogen-free conditions. An Ant2 conditional knockout vector was constructed using the recombineering system. An 8.8-kb genomic DNA fragment of Ant2 was retrieved from a bacterial artificial chromosome DNA clone (129S7/AB2.2 library) ${ }^{39}$ and inserted into pLMJ235 possessing the herpes simplex virus thymidine kinase (HSV-TK) gene as a negative selection marker.

A loxP sequence and an frt-SD/SA-IRES-LacZ-Neo-frt-loxP (SIBN) cassette including a reporter (LacZ) and a positive selection marker (Neo, neomycin-resistant gene) were inserted 131-bp upstream of exon 2 and 189-bp downstream of exon 3, respectively. The linearized targeting vector was electroporated into $\mathrm{J} 1$ embryonic stem (ES) cells and the correct ES cell clone was injected into blastocysts by standard methods. Chimeric male mice were mated with C57BL/6 (B6) females to establish the Ant2 ${ }^{S / B N}$ strain on a 129/B6 hybrid background. All animal experiments were conducted after approval by the Institutional Animal Care and Use Committee of Gachon University (Incheon, South Korea) and the University of Florida (Gainesville, FL, USA).

Generation of Ant2 $2^{2 f / Y}$ and Ant2 ${ }^{1 f / Y}$ ES cells. Ant $2^{2 f / Y}$ and $A n t 2^{1 f / Y}$ ES cells were generated by transfection of Flp- and Cre-expressing vectors into Ant2 ${ }^{\mathrm{SIBN} / Y}$ ES cells, respectively. After the transfection, clones expressing Flp were negatively selected by susceptibility to G418. Clones harboring the Cre vector were selected by resistance to puromycin. Among the selected clones, the genotypes were confirmed as follows.

Genotyping by southern blot analysis and PCR. Genomic DNA isolated from ES cells and mouse tails were digested with EcoRV and Ndel, respectively. Correct homologous recombination between the knockout vector and the endogenous Ant2 locus was confirmed by Southern blot analysis using the external probes (Supplementary Figure S1), as described previously. ${ }^{16}$ Genotyping of the targeted allele was also confirmed by PCR. Primer sequences used were: 5'-ATGGTGCTGCTCAATTCTTAAACA-3' (F7) and 5'-CTGATGGATAGGAAGAA GGCAATA-3' (R7) for WT and Ant2 ${ }^{\text {SIBNN; }}$ 5'-ATACAGCTCGGTGGTAGAGCATTA (F9) and $5^{\prime}$-AGCACAGGCATTGACTGGAGAACA (R9) for Ant2 ${ }^{2 f / Y}$; and F7 and R9 for Ant2 $2^{1 / Y}$. 
Quantitative PCR. Quantitative RT-PCR for Ant1 and Ant2 was performed as we described previously. ${ }^{14}$ For mitochondrial DNA copy number, genomic DNA was isolated from each organ by DNeasy Blood \& Tissue Kit (Qiagen, Valencia, CA, USA). $18 \mathrm{~S}$ (forward, 5'-TAGAGGGACAAGTGGCGTC- $3^{\prime}$ and reverse, 5 '-CGCT GAGCCAGTCAGTGT-3') ${ }^{40}$ and NADH dehydrogenase subunit I (forward, $5^{\prime}-\mathrm{CC}$ CATTCGCGTTATTCTT- $3^{\prime}$ and reverse $5^{\prime}$-AAGTTGATCGTAACGGAAGC- $\left.3^{\prime}\right)^{41}$ primers were used for nuclear and mitochondrial DNA detection, respectively.

Immunoblot analysis. Immunoblot analysis was performed as we described previously. ${ }^{16}$ Rabbit polyclonal anti-ANT-1 antibody and rabbit monoclonal anti- $\beta$ actin antibody were from Sigma-Aldrich (St. Louis, MO, USA, SAB2105530) and Cell Signaling (Danvers, MA, USA, 4970), respectively. Rabbit polyclonal anti-ANT2 antibody was generated by immunization with KLH-conjugated N-terminus ANT2 peptide (NH-TDAAVSFAKDFLAG-COOH) at Lampire Biological Laboratories (Ottsville, PA, USA) and purified with protein G (GE Healthcare, Buckinghamshire, UK) and antigen-conjugated columns. PARP, caspase-3 and cleaved caspase-3 antibodies were from Cell Signaling (9542, 9662 and 9661). Catalase and SOD2 antibodies were from Sigma (St. Louis, MO, USA, C0979) and Abcam (Cambridge, UK, ab16956), respectively.

Flow cytometry analysis. After lysing red blood cells (RBCs), bone marrow (BM) and spleen cells were labeled with various antibodies and subjected to flow cytometry analysis using LSR-II (BD Bioscience, San Jose, CA, USA). FACSDiva (BD Bioscience) was used for data acquisition and analysis. Antibodies used in the study were against: Ter119 (11-5921), CD71 (17-0711), B220 (11-0452, 48-0452), CD43 (12-0439), IgM (17-5790), IgD (11-5993), CD4 (17-0041), and CD8 (11-0081) (eBioscience, San Diego, CA, USA); c-Kit (553355) and Sca1 (557405) (BD Pharmingen, San Jose, CA, USA). The lineage cocktails were PE-Cy7-conjugated anti-CD3 (CT-CD3), anti-CD4 (CT-CD4), anti-CD8 (CT-CD8a), anti-CD45R (RA36B2), anti-CD11b (M1/70.15), anti-Gr-1 (RB6-8C5) and anti-TER-119 (TER-119) (eBioscience). Mitochondrial membrane potential was measured by TMRM staining (ImmunoChemistry Technologies, Bloomington, MN, USA). The level of mitochondrial superoxide anion was assessed using MitoSOX (Invitrogen, Carlsbad, CA, USA) 42 $^{2}$ and cell death was determined by Annexin V and 7AAD staining (BD Pharmingen) $)^{43}$ as we described previously. MPTP was assessed by MitoProbe Transition Pore Assay Kit (Life Technologies, Carlsbad, CA, USA). ${ }^{44}$ Briefly, $1-3 \times 10^{6}$ cells in Hank's balanced salt solution buffer with $10 \mathrm{mM}$ 4-(2-hydroxyethyl)-1-piperazineethanesulfonic acid were incubated at $37^{\circ} \mathrm{C}$ with $1 \mu \mathrm{M}$ calcein AM and $10 \mu \mathrm{M} \mathrm{CoCl}_{2}$ after 10 min preincubation with $1 \mu \mathrm{M} \mathrm{CsA}$ or a vehicle control. Propidium iodide (PI, $1 \mu \mathrm{g} / \mathrm{ml})$ was added right before running on the flow cytometry. Calcein AM fluorescence intensity was evaluated in $\mathrm{PI}-$ cell population.

Cellular ATP levels. Intracellular ATP levels were assayed from freshly prepared splenocytes using ATPlite (Perkin-Elmer, Waltham, MA, USA) according to the manufacturer's instructions. Luminescence was measured using a Synergy HT microplate reader (BioTek, Winooski, VT, USA).

Oxygen consumption rate. XF24 cell culture microplates (Seahorse Bioscience, North Billerica, MA, USA) were pretreated by coating with Cell-Tak (BD Bioscience). A total of $5-10 \times 10^{5}$ splenocytes or thymocytes per XF24 well were seeded in triplicate thereafter. One millimolar sodium pyruvate and $4.5 \mathrm{~g} / \mathrm{l}$ glucose were mixed with XF assay media. The inhibitors were injected during the measurements with final concentrations of $1 \mu \mathrm{M}$ oligomycin, $1 \mu \mathrm{M} \mathrm{FCCP,} 1 \mu \mathrm{M}$ antimycin $\mathrm{A}$ and $1 \mu \mathrm{M}$ rotenone.

Blood count. PB was collected via heart puncture using heparinized syringes and submitted to the core of Animal Care Service at the University of Florida for complete blood count by Hemavet HV950FS (Drew Scientific, Dallas, TX, USA).

Colony forming cell assays. For the CFU-GM assay, RBC lysed BM cells or FL cells from E14.5 embryos ( $1 \times 10^{4}$ per dish) were seeded into $35 \mathrm{~mm}$ dishes in MethoCult GF (StemCell Technologies, Vancouver, BC, Canada). For the CFU-E assay, RBC lysed BM or FL cells $\left(8 \times 10^{4}\right.$ per dish for $\mathrm{BM}, 2 \times 10^{4}$ per dish for $\left.\mathrm{FL}\right)$ were plated in MethoCult M3334 (StemCell Technologies). Cultures were maintained at $37^{\circ} \mathrm{C}$ under humidified conditions with $5 \% \mathrm{CO}_{2}$. The colonies were counted within day 7 for GFU-E and day 12 for CFU-GM colonies.
BM transplantation. B6 recipient mice (Jackson Laboratory, Bar Harbor, ME, USA) were lethally irradiated at $1000 \mathrm{rad}$ in $6-8 \mathrm{~h}$ before transplantation. Isolated BM cells $\left(2 \times 10^{6}\right)$ from P17 to 19 donors were transplanted by tail vein injection.

Statistical analysis. Statistical significance between groups was determined using either Student's t-tests or ANOVA in Prism (GraphPad Software, La Jolla, CA, USA).

\section{Conflict of Interest}

The authors declare no conflict of interest.

Acknowledgements. We thank Dr. Laurence Morel (University of Florida) for providing antibodies for hematopoietic precursor sorting, Dr. Brian Harfe for the Flp vector, Drs. Clayton Matthews, William Dunn, Chen Liu and W Strat May for helpful discussion and technical advice and Dr. Katherine Santostefano for critical reading of the manuscript. We also appreciate Dr. Robert Anderson (Newcastle University, UK) for his advice on cardiac histology. This research was supported in part by National Institutes of Health Grants (HD060474 to NT; DK079879 and DK090115 to JK), and a research grant from Otsuka Maryland Medicinal Laboratories to NT.

\section{Author contributions}

$\mathrm{JC}$ performed research, analyzed data, designed research and wrote the paper; JS, CHL, TS, M-HL, RRC performed research; YJL, HK, J-SK analyzed data; SPO analyzed data and designed research; YJL performed research, analyzed data and designed research; and NT designed research, analyzed data and wrote the paper.

1. Klingenberg M. Molecular aspects of the adenine nucleotide carrier from mitochondria. Arch Biochem Biophys 1989; 270: 1-14

2. Nelson DR, Felix CM, Swanson JM. Highly conserved charge-pair networks in the mitochondrial carrier family. J Mol Biol 1998; 277: 285-308.

3. Fiore C, Trézéguet V, Le Saux A, Roux P, Schwimmer C, Dianoux AC et al. The mitochondrial ADP/ATP carrier: structural, physiological and pathological aspects. Biochimie 1998; 80: 137-150.

4. Duszyński J, Bogucka K, Letko G, Küster U, Kunz W, Wojtczak L. Relationship between the energy cost of ATP transport and ATP synthesis in mitochondria. Biochim Biophys Acta 1981; 637: 217-223.

5. Klingenberg M. The ADP and ATP transport in mitochondria and its carrier. Biochim Biophys Acta 2008; 1778: 1978-2021.

6. Doerner A, Pauschinger M, Badorff A, Noutsias M, Giessen S, Schulze K et al. Tissue-specific transcription pattern of the adenine nucleotide translocase isoforms in humans. FEBS Lett 1997; 414: 258-262.

7. Chinopoulos C, Vajda S, Csanády L, Mándi M, Mathe K, Adam-Vizi V. A novel kinetic assay of mitochondrial ATP-ADP exchange rate mediated by the ANT. Biophys $J$ 2009; 96 : 2490-2504

8. Vyssokikh MY, Katz A, Rueck A, Wuensch C, Dörner AZorov DB et al. Adenine nucleotide translocator isoforms 1 and 2 are differently distributed in the mitochondrial inner membrane and have distinct affinities to cyclophilin D. Biochem J 2001; 358 (Part 2): 349-358.

9. Brand MD, Pakay JL, Ocloo A, Kokoszka J, Wallace DCBrookes PS et al. The basal proton conductance of mitochondria depends on adenine nucleotide translocase content. Biochem J 2005; 392 (Part 2): 353-362.

10. Sharer JD, Shern JF, Van Valkenburgh H, Wallace DC, Kahn RA. ARL2 and BART enter mitochondria and bind the adenine nucleotide transporter. Mol Biol Cell 2002; 13: 71-83.

11. Zoratti M, Szabò I. The mitochondrial permeability transition. Biochim Biophys Acta 1995; 1241: 139-176.

12. Stepien G, Torroni A, Chung AB, Hodge JA, Wallace DC. Differential expression of adenine nucleotide translocator isoforms in mammalian tissues and during muscle cell differentiation. J Biol Chem 1992; 267: 14592-14597.

13. Levy SE, Chen YS, Graham BH, Wallace DC. Expression and sequence analysis of the mouse adenine nucleotide translocase 1 and 2 genes. Gene 2000; 254: 57-66.

14. Brower JV, Lim CH, Han C, Hankowski KE, Hamazaki T, Terada N. Differential CpG island methylation of murine adenine nucleotide translocase genes. Biochim Biophys Acta 2009; 1789: 198-203.

15. Rodic N, Oka M, Hamazaki T, Murawski MR, Jorgensen MMaatouk DM et al. DNA methylation is required for silencing of ant4, an adenine nucleotide translocase selectively expressed in mouse embryonic stem cells and germ cells. Stem Cells 2005; 23: 1314-1323.

16. Brower JV, Rodic N, Seki T, Jorgensen M, Fliess N, Yachnis AT et al. Evolutionarily conserved mammalian adenine nucleotide translocase 4 is essential for spermatogenesis. J Biol Chem 2007; 282: 29658-29666.

17. Kehoe SM, Oka M, Hankowski KE, Reichert N, Garcia SMcCarrey JR et al. A conserved E2F6-binding element in murine meiosis-specific gene promoters. Biol Reprod 2008; 79: 921-930. 
18. Chevrollier A, Loiseau D, Reynier P, Stepien G. Adenine nucleotide translocase 2 is a key mitochondrial protein in cancer metabolism. Biochim Biophys Acta 2011; 1807: 562-567.

19. Graham BH, Waymire KG, Cottrell B, Trounce IA, MacGregor GR, Wallace DC. A mouse model for mitochondrial myopathy and cardiomyopathy resulting from a deficiency in the heart/muscle isoform of the adenine nucleotide translocator. Nat Genet 1997; 16: 226-234.

20. Brower JV, Lim CH, Jorgensen M, Oh SP, Terada N. Adenine nucleotide translocase 4 deficiency leads to early meiotic arrest of murine male germ cells. Reproduction 2009; 138 : 463-470.

21. Kokoszka JE, Waymire KG, Levy SE, Sligh JE, Cai J, Jones DP et al. The ADP/ATP translocator is not essential for the mitochondrial permeability transition pore. Nature 2004; 427: 461-465.

22. Hofker MH, Deursen Jv. Transgenic Mouse Methods and Protocols, 2nd edn. Humana Press: New York, NY, USA, 2011.

23. Esposito LA, Melov S, Panov A, Cottrell BA, Wallace DC. Mitochondrial disease in mouse results in increased oxidative stress. Proc Natl Acad Sci USA 1999; 96: 4820-4825.

24. Halestrap AP, Brenner $C$. The adenine nucleotide translocase: a central component of the mitochondrial permeability transition pore and key player in cell death. Curr Med Chem 2003; 10: $1507-1525$.

25. Kim HS, Je JH, Son TG, Park HR, Ji ST, Pokharel YR et al. The hepatoprotective effects of adenine nucleotide translocator-2 against aging and oxidative stress. Free Radic Res 2012; 46: $21-29$.

26. Ho L, Titus AS, Banerjee KK, George S, Lin W, Deota S et al. SIRT4 regulates ATP homeostasis and mediates a retrograde signaling via AMPK. Aging (Albany, NY) 2013; 5: 835-849.

27. Park JI, Kim SG, Baek MW, Park TJ, Lim IK, Seo YW et al. B-cell translocation gene 2: expression in the rat ovary and potential association with adenine nucleotide translocase 2 in mitochondria. Mol Cell Endocrinol 2013; 367: 31-40.

28. Wallace DC, Fan W. The pathophysiology of mitochondrial disease as modeled in the mouse. Genes Dev 2009; 23: 1714-1736.

29. Dogan SA, Trifunovic A. Modelling mitochondrial dysfunction in mice. Physiol Res 2011; 60: S61-S70.

30. Inoue S, Yokota M, Nakada K, Miyoshi H, Hayashi J. Pathogenic mitochondrial DNA-induced respiration defects in hematopoietic cells result in anemia by suppressing erythroid differentiation. FEBS Lett 2007; 581: 1910-1916.
31. Chen ML, Logan TD, Hochberg ML, Shelat SG, Yu X, Wilding GE et al. Erythroid dysplasia megaloblastic anemia, and impaired lymphopoiesis arising from mitochondrial dysfunction. Blood 2009; 114: 4045-4053.

32. Kuma A, Hatano M, Matsui M, Yamamoto A, Nakaya $H$, Yoshimori $T$ et al. The role of autophagy during the early neonatal starvation period. Nature 2004; 432: 1032-1036.

33. Pua HH, Dzhagalov I, Chuck M, Mizushima N, He YW. A critical role for the autophagy gene Atg5 in T cell survival and proliferation. J Exp Med 2007; 204: 25-31.

34. Miller BC, Zhao Z, Stephenson LM, Cadwell K, Pua HH, Lee HK et al. The autophagy gene ATG5 plays an essential role in B lymphocyte development. Autophagy 2008; 4: 309-314.

35. López LC, Akman HO, García-Cazorla A, Dorado B, Martí R, Nishino I et al. Unbalanced deoxynucleotide pools cause mitochondrial DNA instability in thymidine phosphorylasedeficient mice. Hum Mol Genet 2009; 18: 714-722.

36. Haraguchi M, Tsujimoto H, Fukushima M, Higuchi I, Kuribayashi H, Utsumi H et al. Targeted deletion of both thymidine phosphorylase and uridine phosphorylase and consequent disorders in mice. Mol Cell Biol 2002; 22: 5212-5221.

37. Hirano M, Silvestri G, Blake DM, Lombes A, Minetti C, Bonilla E et al. Mitochondrial neurogastrointestinal encephalomyopathy (MNGIE): clinical, biochemical, and genetic features of an autosomal recessive mitochondrial disorder. Neurology 1994; 44: 721-727.

38. Hirano M, Martí R, Spinazzola A, Nishino I, Nishigaki Y. Thymidine phosphorylase deficiency causes MNGIE: an autosomal recessive mitochondrial disorder. Nucleosides Nucleotides Nucleic Acids 2004; 23: 1217-1225.

39. Adams DJ, Quail MA, Cox T, van der Weyden L, Gorick BD, Su Q et al. A genome-wide, end-sequenced 129Sv BAC library resource for targeting vector construction. Genomics 2005; 86: 753-758.

40. Bai RK, Perng CL, Hsu CH, Wong LJ. Quantitative PCR analysis of mitochondrial DNA content in patients with mitochondrial disease. Ann NY Acad Sci 2004; 1011: 304-309.

41. Medeiros DM. Assessing mitochondria biogenesis. Methods 2008; 46: 288-294.

42. Cho JS, Kook SH, Robinson AR, Niedernhofer LJ, Lee BC. Cell autonomous and nonautonomous mechanisms drive hematopoietic stem/progenitor cell loss in the absence of DNA repair. Stem Cells 2013; 31: 511-525.

43. Cho J, Shen H, Yu H, Li H, Cheng T, Lee SB et al. Ewing sarcoma gene Ews regulates hematopoietic stem cell senescence. Blood 2011; 117: 1156-1166.

44. Gao J, Sana R, Calder V, Calonge M, Lee W, Wheeler LA et al. Mitochondrial permeability transition pore in inflammatory apoptosis of human conjunctival epithelial cells and $\mathrm{T}$ cells: effect of cyclosporin A. Invest Ophthalmol Vis Sci 2013; 54: 4717-4733.

Supplementary Information accompanies this paper on Cell Death and Differentiation website (http://www.nature.com/cdd) 